\section{Procedencia y uso de madera de pino silvestre y pino laricio en edificios históricos de Castilla y Andalucía}

\section{Origin and use of scots and black timber pine in historic buildings from Castile and Andalusia}

\author{
EdUARDO RodRÍGUEZ TROBAJO \\ Centro de Investigación Forestal, I.N.I.A. Madrid*
}

\section{Resumen}

Se realiza un recorrido a través del ciclo constructivo de las maderas de pino silvestre (Pinus sylvestris L.) y pino laricio (Pinus nigra Arn.) en el ámbito de la carpintería medieval de Castilla y Andalucía. Nuevos criterios para diferenciar las dos especies de madera y su datación

dendrocronológica, son aportados como datos previos para determinar el origen geográfico del material. Son objeto de discusión los nombres históricos de estas especies y otras voces, como alerce, que tienen una imprecisa asignación. Se identifican así las principales áreas históricas de aprovechamiento y las vías fluviales del Tajo y Guadalquivir utilizadas para el abastecimiento de madera de pino laricio a poblaciones del interior peninsular (Sevilla, Toledo, Madrid, etc.).

Por otra parte, se analizan la diversificación de maderas y su uso selectivo en función del valor resistente de cada especie. Así mismo, las condiciones de disponibilidad determinan que un tipo de madera se convierta en fósilguía (especie-guía), que se propone como indicador cronológico de varios periodos y contextos constructivos. Finalmente, se estudian más en detalle restos lígneos del primer milenio de la Era, pertenecientes a la Mezquita de Córdoba y cuatro iglesias altomedievales de la cuenca del Duero (La Nave, Baños, Quintanilla y Barriosuso). La datación empírica y el análisis de este material aportan una cronología post quem de la construcción de estos edificios y también nuevos datos sobre la distribución de estas especies en la región norte de la Península Ibérica.

Palabras clave: madera, alerce, Pinus sylvestris, Pinus nigra, dendrocronología, datación carbono-14, fósil-guía, alto medieval, reutilización.

\begin{abstract}
The productive cycle of Scots pine (Pinus sylvestris L.) and black pine (Pinus nigra Arn.) within the medieval Castilian and Andalusian carpentry is here analysed. New criteria to identify both timbers and its dendrochronological date are shown as previous facts to determine their geographical origin. Historical names of these species and other names, such as alerce, with a vague allocation are also studied. Main historical areas of resource and river ways of Tajo and Guadalquivir used to transport the wood (black pine) to interior cities (Sevilla, Toledo, Madrid ...) are thus identified.

On the other hand, wood's diversification and its selective use is analysed regarding its resistance value. Availability also determines that a sort of wood becomes fossil-guide (especie-guía), which is proposed as chronological indicator for several periods and constructive contexts. Some timber remains dating to the first millennium are studied in detail. They belong to the Mosque of Cordoba and four early medieval churches sited in the Duero valley (La Nave, Baños, Quintanilla and Barriosuso). The empiric dating and analysis of this material offer a post quem chronology for the building of these churches and new facts about the distribution of theses wood's species in the north-western Iberian peninsula.
\end{abstract}

Key words: wood, alerce, Pinus sylvestris, Pinus nigra, dendrochronology, carbon-14, fossil-guide, Early Medieval, reusing.

*trobajo@inia.es

\section{DOS MADERAS AFINES CON VALOR CRONOLÓGICO}

Tan pronto un tronco de pino laricio (Pinus nigra Arn. subs. salzmannii (Dunal) Franco) es labrado en piezas escuadradas, surge la cuestión de identificar su madera. El problema radica en la proximidad taxonómica entre el pino laricio y el silvestre (Pinus sylvestris L.), con el que comparte también un carácter higrófilo y microtérmico. Aunque las dos especies no tienden a formar masas mixtas, es frecuente encontrarlas próximas entre sí en niveles altitudinales medios y altos del área mediterránea peninsular. Ambas maderas tienen caracteres diagnósticos comunes, como punteaduras tipo pinoide I, que les diferencian de otras especies de pino más xerófilas: el pino pinaster ( $P$. pinaster Ait.), el carrasco ( $P$. halepensis Mill.) y el piñonero $(P \text { p pinea L. })^{1}$. Se han propuesto nuevos caracteres diagnósticos (PALACIOS, 1997), pero no se ha logrado una diferenciación segura entre ambas maderas.

En la bibliografía arqueobotánica se refleja esta indeterminación con términos como pino albar-laricio, o Pinus tipo sylvestris-nigra (BUXÓ y PIQUÉ, 2008), y lo mismo sucede con el polen de las dos especies que tampoco es posible diferenciar (RAmil et al., 2001). Tan sólo la presencia de algunos macrorrestos como las piñas han permitido una identificación segura de la especie (RoIG et al., 1997). Ante esta situación, se puede utilizar el recurso de deducir la pertenencia a una u otra especie en razón de la proximidad de sus masas naturales. Al hacer esto invertimos el orden del análisis arqueológico, ya que sería a partir de la identificación de la madera como debería inferirse el origen geográfico. Además, en el contexto de un comercio activo de madera, este criterio no es válido, dado que el material pudo ser transportado desde regiones distantes. Por otra parte, si se trata de madera de cierta edad, sería arriesgado suponer que la distribución natural de las dos especies era similar a la actual; en este caso, además del posible error de identificación, nos encontramos ante la dificultad de conocer la distribución real y grado de aprovechamiento que las dos especies tuvieron en el pasado.

\footnotetext{
${ }^{1}$ Como es sabido, los nombres vulgares de las especies de pino basados en coloraciones son equívocos al pasar de una región a otra (RUIZ DE LA TORRE, 1979). Así, en Castilla La Vieja se denomina pino negral a Pinus pinaster, pero en Cuenca y Teruel este nombre se asigna a $P$. nigra, mientras que $P$. pinaster es conocido como pino rodeno (propio de areniscas rojas). De igual modo, $P$. sylvestris es llamado albar en muchas regiones, pero en Castilla La Vieja se reserva este nombre para el piñonero, $P$. pinea. Incluso, $P$. nigra recibe el nombre de pino blanco en Segura de Huescar y también P. halepensis es llamado pino blanquillo en Cazorla y Segura y pi blanc en Cataluña. Para evitar estos equívocos, hemos optado por los nombres indicados en el texto, si bien se hará alusión a las diversas denominaciones actuales e históricas que han recibido estas especies.
} 
Por consiguiente, resulta de utilidad disponer de algún criterio adicional que permita diferenciar estas maderas. La proporción albura-duramen en el pino laricio muestra un número de años de duramen netamente inferior al de la madera de silvestre (GUTIÉRREZ Oliva, comunicación personal). Se puede observar esta diferencia, por ejemplo, en secciones de troncos con 150 años de edad en las que el duramen tiene $66 \pm 26$ anillos, si se trata de pino silvestre, mientras que si fuesen de laricio tendría $28 \pm$ 15 anillos. Otra propiedad distintiva es el desarrollo relativo de la madera de tipo juvenil y madura, cuyo límite se sitúa en el pino silvestre en $22 \pm 7$ (MUTZ et al., 2004), mientras que en el laricio se produce a los $48 \pm 13$ años, momento en el que su densidad alcanza sus valores máximos, $547 \pm 54 \mathrm{~kg} / \mathrm{m}^{3}$ (RODRÍGUEZ y ORTEGA, 2006). Asimismo esta notable densidad distingue al pino laricio del resto de coníferas españolas y es causa de que su madera sea hasta $20 \%$ y $30 \%$ más resistente que las de pino silvestre y pinaster, respectivamente (FERNÁNDEZ-GOLFín et al., 2001).

El pino laricio destaca sobre el resto de pinos peninsulares por su notable longevidad. Así, mientras un pino silvestre de 300-400 años se acerca a su edad límite, no es infrecuente encontrar secuencias de pino laricio tan largas en edificios históricos. Si nos referimos a árboles en pie debemos citar los ejemplares de laricio de Puerto LLano en Sierra Cazorla que superan los 1000 años de edad (Creus y PUig de FÁbregas, 1983). Otro carácter a veces distintivo entre laricio y silvestre es el mayor contenido de resina del laricio, siendo también peculiar de esta madera el enteado. Estas diferencias genéticas y eco-fisiológicas tienen como contrapartida la mayor proclividad del pino laricio a desarrollar anomalías de crecimiento. Típicamente se observan grupos de anillos en «abanico» que llegan a desaparecer (figura 1) y cuya perdida invalida la secuencia anular. Afortunadamente, esta anomalía tiene carácter individual y es posible, por tanto, su corrección sobre un grupo amplio de muestras.

Sin embargo, la diferenciación de las dos especies no siempre es posible, ya que el labrado de piezas suele eliminar los caracteres de diferenciación indicados anteriormente $y$, de este modo, incrementa el riesgo de aceptar una procedencia errónea del material. Por otra parte, la pérdida de la madera más externa por labrado afecta también a la datación dendrocronológica que se limita así a una acotación del año de tala del árbol (datación post quem). En este caso, la estimación de anillos perdidos deberá basarse en la proporción albura-duramen que, tal como hemos indicado, difiere bastante en una y otra

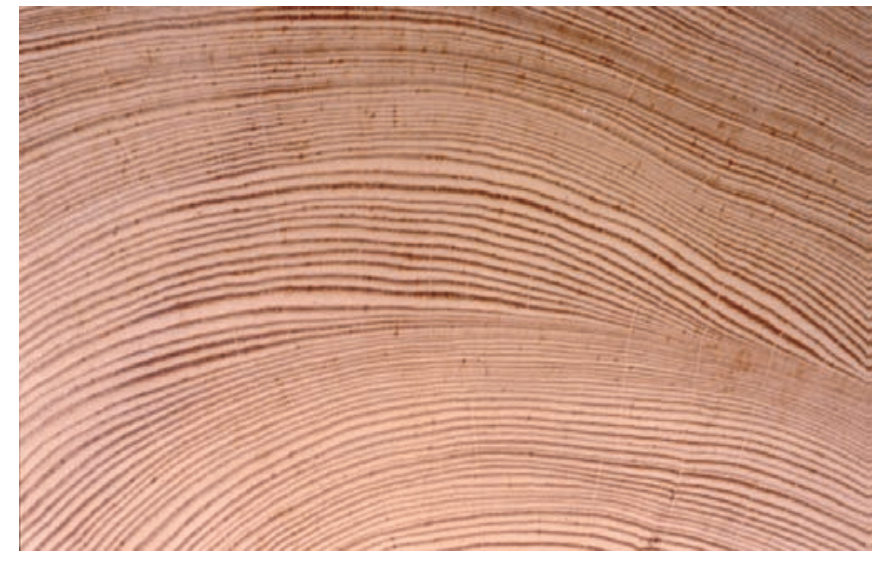

Fig. 1: Anomalía de anillos ausentes en una muestra de pino laricio de Sierra de Segura

especie, por lo que la estimación no podrá ser firme si desconocemos su identidad.

Hasta aquí hemos utilizado caracteres cronológicos internos para tratar de solventar el problema de diferenciación entre pino silvestre y laricio. Ahora corresponde valorar sus propiedades cronológicas externas y su idoneidad para la datación dendrocronológica. Ya en algunos estudios iniciales (RICHTER y RODRíGUEZ, 1986) pudimos comprobar la interconexión de series de los pinos silvestre y laricio con otras especies del género Pinus situadas en localidades más o menos distantes entre sí. De este modo, las cronologías de referencia de ambas especies son válidas para la dendrodatación de estructuras lígneas que utilicen cualquier especie de pino. Por el contrario, los algoritmos de similitud entre series dendrocronológicas de estas especies no son buenos factores discriminantes para determinar el origen geográfico del material, ya que se pueden encontrar similitudes mayores entre masas alejadas que entre las de la misma región.

Las masas naturales de silvestre y laricio ocupan actualmente áreas próximas entre sí en los Sistemas Pirenaico e Ibérico. Por el contrario, en el Sistema Central y Sierra Nevada las formaciones de silvestre tienen mayor extensión, mientras que en las Sierras Béticas es el pino laricio el predominante (CATALÁN et al., 1991). La fragmentación de masas y la presencia de manchas aisladas de carácter relícto indican que la distribución natural de ambas especies fue más amplia en el pasado, y que los procesos de deforestación, por roturación y sobreexplotación, han tenido un efecto determinante en su reducción actual. En relación a esto, la presencia de madera en construcciones históricas es una fuente material directa para conocer la distribución de estas especies en el pasado.

En el presente trabajo abordamos el estudio del ciclo 
constructivo de la madera de pino silvestre y laricio en una amplia región interior de la Península Ibérica, que incluye las dos Castillas y Andalucía, en donde las masas naturales de estas especies han experimentado una evolución en función del nivel de aprovechamiento y uso que han tenido en nuestra carpintería histórica. En el orden metodológico utilizamos el análisis dendrocronológico como método empírico de datación, pero al mismo tiempo, como instrumento de análisis ecofactual (identificación y procedencia) y artefactual (uso constructivo y degradación).

\section{ÁREAS FORESTALES Y ESPECIES-GUÍA}

La presencia de una especie está condicionada por la situación de sus masas maderables y susceptibles de aprovechamiento. A su vez, la procedencia del material es cuestión básica del análisis arqueológico de una construcción, ya que el acceso y abundancia del recurso condiciona su utilización y el desarrollo de modos y tipos constructivos determinados. En la carpintería medieval española, la adaptación al recurso lígneo se refleja en la utilización de fuentes de aprovechamiento múltiples, de manera que es frecuente encontrar varias especies de madera en una misma construcción. Si nos circunscribimos al área mediterránea peninsular la madera más frecuente es un pino xerófilo, pinaster o carrasco dependiendo de la región, junto a otras especies locales, cuyo origen suele localizarse a distancias cortas o medias de la propia construcción. Por el contrario, la presencia de los pinos silvestre y laricio, implica generalmente un transporte a distancias apreciables, desde las áreas forestales de estas especies situadas en las cabeceras de las cuencas y por encima de $1000 \mathrm{~m}$ de altitud.

Las primeras referencias documentales al aprovechamiento de pino laricio se remontan al siglo $\mathrm{X}$, cuando el geógrafo Al-Razi (LÉVI-PROVENÇAL, 1953) pondera la abundancia de madera de las sierras del alto Guadalquivir y su capacidad de abastecer a todo al-Andalus. En particular, Quesada (Qaysata) tenía una floreciente industria de utensilios de madera que se exportaban al Magreb (AGUIRRE y JIMÉNEZ, 1979). Los modos de transporte de esta madera parecen consolidados y se basan en buena medida en las vías fluviales. Así, en referencia al pino laricio de la Serranía de Cuenca, Alfonso VIII otorgaba en 1192 a la orden de Calatrava parte del diezmo que se pagaba en Toledo por la madera que descendía por el Tajo hacia la frontera (CARLE, 1976). En 1154 el geógrafo al-Idrisi describe el descenso por el «río de Quelaza» (Júcar) de gran número de pinos (laricios) hasta el mar con destino a las construc- ciones naval (Denia) y de edificios (Valencia). El transporte fluvial se mantuvo en siglos posteriores y, en 1238, Jaime I concede a Valencia el derecho de aprovisionarse de la madera sacada por el Guadalaviar y el Júcar (SANCHís y PIQUERAS, 2001)². Asimismo, Alfonso X recurre a la madera del alto Guadalquivir para abastecer las atarazanas sevillanas, aunque en este momento se necesitaba traer también madera de regiones más distantes como Galicia (GARCía DE CORTÁZAR, 1973). El comercio de madera alcanzó tal escala en estos siglos, que haría lamentarse a Pedro I en 1351 del excesivo coste y sobreexplotación de la madera, «...ca della se saca por mar e della por rios e della por tierra, $e$ que la llevan a otros sennorios..." (CARLE, 1976).

Hay que considerar, por tanto, que las fuentes de aprovechamiento pueden ser múltiples y distantes entre sí. Un buen ejemplo de esta situación se presenta en la Granada de finales del siglo XIII, cuando se construye un palacio nazarí en el interior de una torre de la muralla de la ciudad, que en época cristiana será llamado Cuarto Real de Sto. Domingo. Este palacio (figura $2 \mathrm{~A}$ ) es la más antigua qubba nazarí conservada y es precursora de las que posteriormente se construirán en la Alhambra (Almagro, 2002); pero tiene también un carácter singular para la carpintería histórica, pues se cubre con una armadura apeinazada de lazo, es decir, construida al modo cristiano, pero realizada por carpinteros musulmanes (NUERE, 2008).

La dendrodatación del Cuarto Real en 1283 post quem (figura 4) se logró a partir de la madera de pino usada en su techumbre (RODRÍGUEZ, en estudio), pero en su construcción se utilizaron hasta 4 especies diferentes de madera: pino silvestre/laricio, pino pinaster, quejigo (Quercus faginea Lamk.) y cedro (Cedrus atlantica (Endl.) Carrière). Esta combinación de especies refleja una diversificación de orígenes, pero al mismo tiempo un uso eficiente del material. La techumbre está compuesta de paneles prefabricados rectangulares y triangulares, en los que cada especie de madera es utilizada en función de sus propiedades resistentes (figura 3). Así, las manguetas y pares torales se labraron en pino, mientras que péndolas, elementos más cortos, y limas moamares, que se emparejan en cada arista, fueron labrados en cedro. El roble (quejigo) se utilizó en

\footnotetext{
${ }^{2}$ Aunque no forma parte de nuestro estudio, debemos mencionar el transporte fluvial de madera que se realizó desde época temprana por el río Ebro. En el fuero de Logroño (1095) se hace referencia a los «rades» como transporte de madera por el río que según Lacarra (1980) deben interpretarse como almadías, la forma tradicional de conducción de madera por el Ebro y sus afluentes pirenaicos. El mismo autor cita un documento de 1187 en el que se autoriza el descenso desde San Millán de la madera necesaria para reparar el puente de Zaragoza.
} 

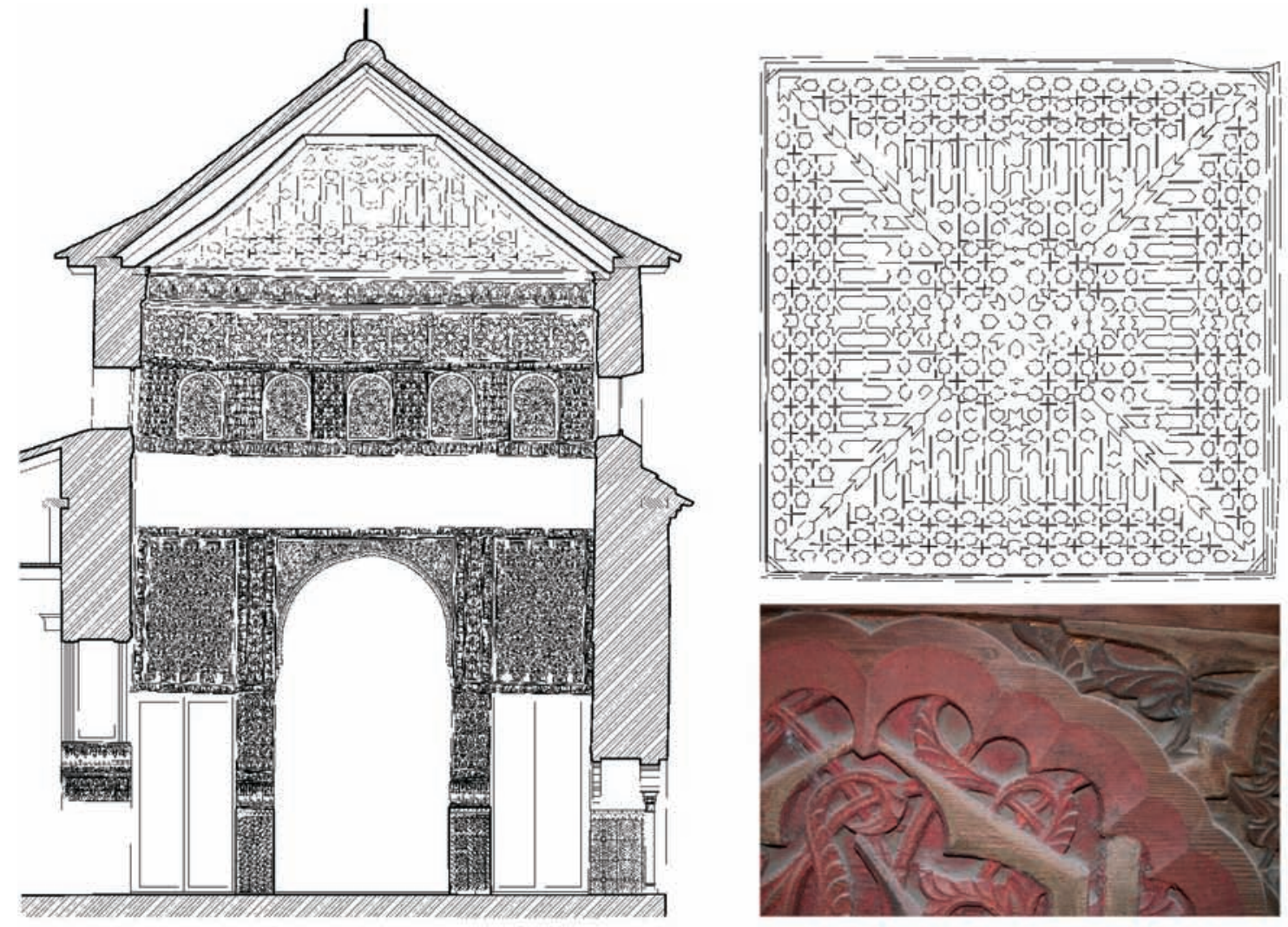

A

CUARTO REAL DE SANTO DOMINGO (GRANADA)
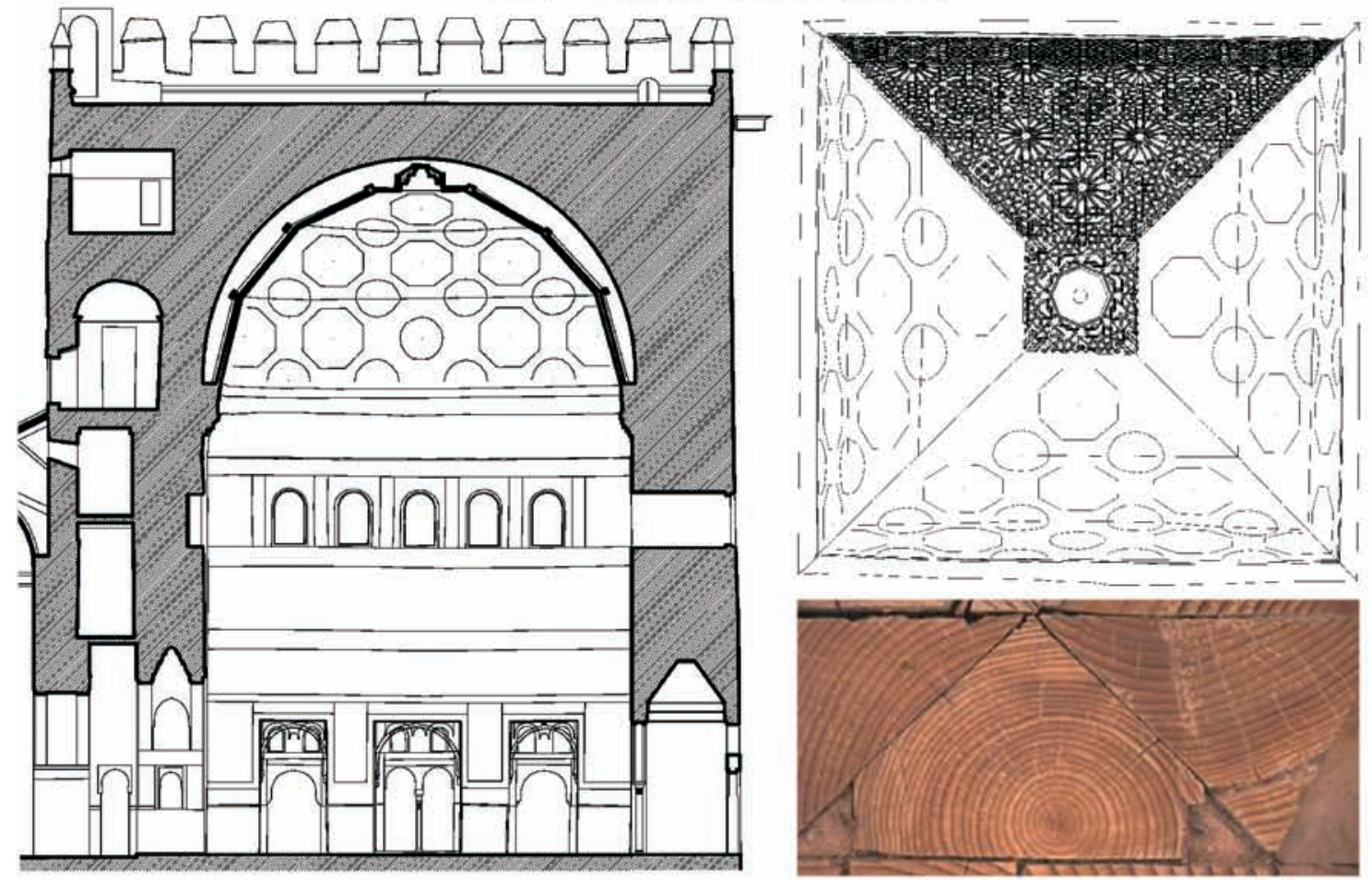

B

TORRE DE COMARES (ALHAMBRA)

Fig. 2. Entre las qubba del Cuarto Real de Sto. Domingo (h. 1281) (A) y de la torre de Comares en la Alhambra (1350) (B) hay cambios conceptuales (ALMAGRO, 2008), que se reflejan también en el modo constructivo de sus techumbres: la primera es apeinazada y simple de un paño, mientras la segunda es ataujerada y de tres paños. Sin embargo, ambas comparten el uso de madera de cedro en sus labores decorativas (A: alicer / B: testas de mocárabes). (Planos de A. ALmAGro GorbeA) 
Fig. 3. Techumbre del Cuarto Real de Sto. Domingo. Cada paño se compone de tres paneles prefabricados con maderas diferentes: manguetas y pares torales de pino pinaster y silvestre/laricio $(\mathrm{Pn})$; péndolas, limas $y$ rosetas de cedro $(\mathrm{Ca})$ y refuerzos de quejigo (Qf)
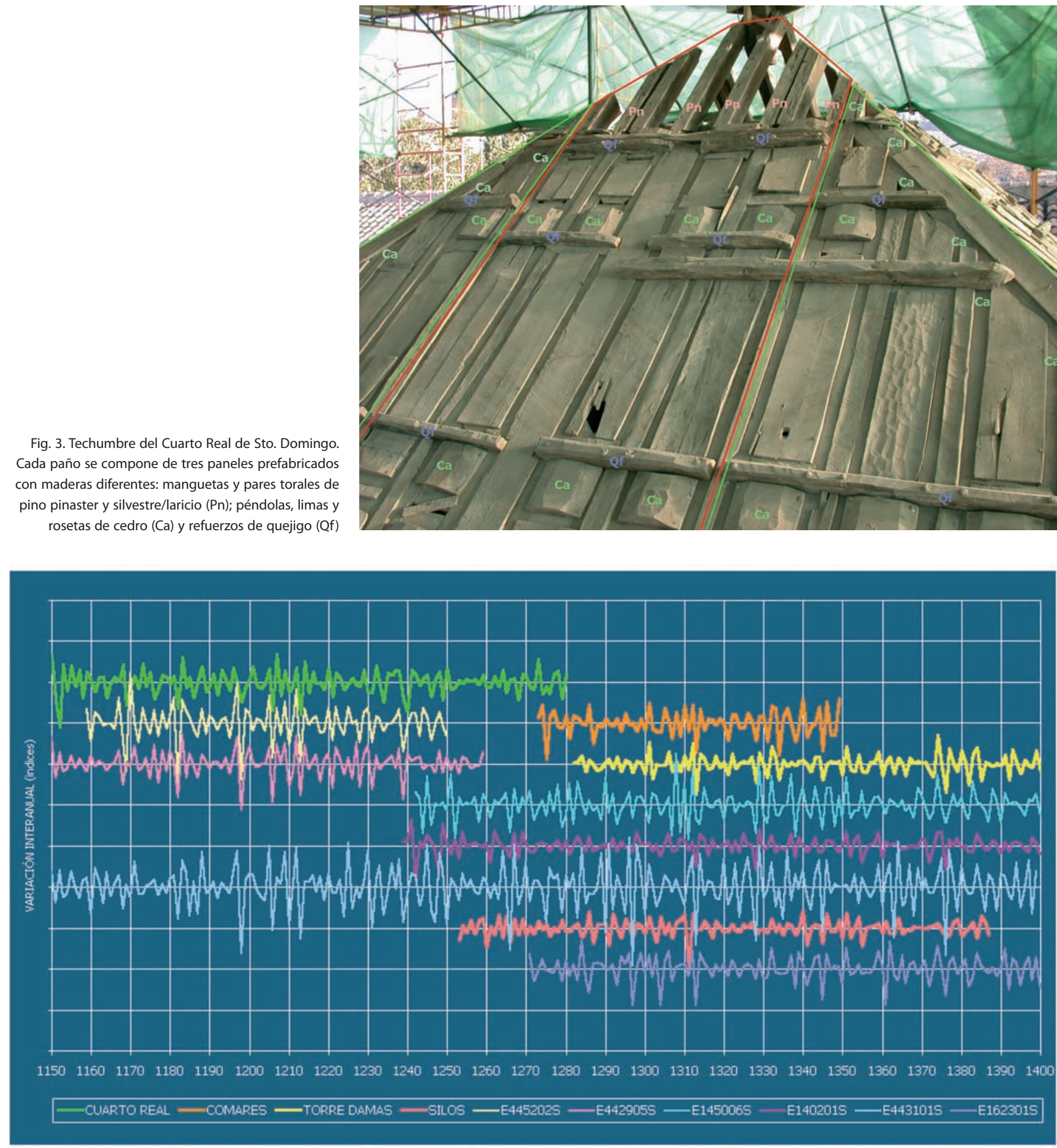

Fig. 4. Interdatación de las estructuras del Cuarto Real de Sto. Domingo (Granada), Torre de Comares y Torre de las Damas en la Alhambra, y Claustro de Silos (Burgos). Las curvas muestran mayor o menor contraste (sensibilidad) en función de la especie de pino y de su respuesta microclimática, que determinan similitudes altas en Cuarto Real ( $\mathrm{t}>7$ ), medias en Comares y Torre Damas ( $t$ : 6-7) y baja en Silos ( $\mathrm{t}<6)$ respecto a diferentes cronologías de referencia

estribos de apoyo de la techumbre y en travesaños de refuerzo de los paneles, mientras que toda la labor de lazos y decoración del intradós, como rosetas excavadas y aliceres, se labraron exclusivamente en cedro. Hay que destacar que el modelo de alfardas dobles adoptado no fue obligado por falta de escuadrías, pues la mayoría de piezas son cuartizos bien escuadrados y proceden, por tanto, de trozas de diámetro holgado. En definitiva, la calidad del material 
utilizado se pone de manifiesto en el corte de cada alicer de una sola pieza, por lo que tuvieron que disponer de grandes trozas de cedro de al menos $50 \mathrm{~cm}$ de diámetro y 7,5 m de longitud.

La procedencia geográfica de este conjunto de maderas muestra una interesante diversidad. Por un lado, el origen del pino pinaster y del quejigo pueden circunscribirse a áreas próximas a Granada, como las Sierras Harana y Huétor (VAlle, 1979). Por el contrario, la madera de pino silvestre/laricio, que no ha podido ser diferenciada, tiene una presencia natural de ambas especies en Sierra Nevada: sobre substrato silíceo, el pino silvestre (Pinus sylvestris L. subsp. nevadensis), y en orlas calizas, el pino laricio (NAVARRO, 1998). Asimismo el pino laricio es espontáneo en sierras más próximas como las de Quéntar y Huétor (Alejano, 2005), o en la más distante Sierra de Baza, donde también se mezclan las dos especies (GÓMEZMercado y Valle, 1990). Por último, no podemos descartar otro posible origen de laricio en las Sierras de Cazorla y Segura por la supuesta inaccesibilidad a territorio cristiano, puesto que cuando se construía este palacio, las incursiones en tierras del Adelantamiento de Cazorla eran continuas y la villa de Quesada estuvo en poder de Granada entre 1295 y 1311 (GARCía, 1985).

Por otro lado, nos encontramos con una madera de origen foráneo como es el cedro, cuyo origen más próximo se localiza en el Atlas del norte de Marruecos. Se trata de Cedrus atlantica, que se extiende por las sierras del Rif próximas a los puertos del litoral. Conocemos el activo comercio en época nazarí entre Almería y Málaga y los puertos de Berbería. En 1344 un barco nazarí venía del puerto de Badis (Vélez de la Gomera) con 320 fustes y 230 remos, supuestamente con destino a Almería (SÁNCHEZ, 1988). En el siglo XV, Al-Ansari señalaba la existencia en Ceuta de bosques de cedros (VALLVÉ, 1962). Según describe León el Africano, en Badis «...hay buenas maderas para construcción de fustas y galeras..." que proceden de las montañas vecinas. Otras noticias sobre este comercio, identifican las maderas como alerzes, e igual nombre les da Luis de Mármol en 1573 en su Descripción General de África. La equivalencia entre alerze y çedrus es claramente expresada en los textos y vocabularios que aparecen entre los siglos XII y XVI y se mantiene en el diccionario de Covarrubias de 1611, en el que se definen las voces Alerce y Alerzo como especie de cedro (cit. FERNÁNDEZ, 1996). En opinión de Ceballos y Ruiz de la Torre (1979), es probable que por los puertos de la Bética se importaran maderas de Cedrus atlantica y de Tetraclinis articulata (Vahl) Masters procedentes de Yebala y Gomara. Por consiguiente, todas estas referencias parecen indicar que el cedro del Cuarto Real pudo recibir el nombre de alerze, sin que podamos aducir, hasta el momento, una prueba documental sobre este extremo.

En cualquier caso, este comercio nazarí de maderas con el norte de África se mantiene en el siglo XIV, pues vuelve a utilizarse el cedro en el conjunto de mocárabes que adornan la techumbre del Salón de Embajadores de la Alhambra (figura 2B). Se trata de una techumbre ataujerada de tres paños (NuERE, 2008), en cuya construcción se combinaron también maderas diferentes en razón de sus propiedades resistentes: pino carrasco (Pinus halepensis) en tablas y vigas de los paños superiores, peralejo (Populus alba L.) en vigas del faldón inferior y estribos y, finalmente, el cedro (Cedrus atlantica) en las adarajas que componen los mocárabes. En este caso la madera que permitió la dendrodatación en 1350 (figura 4) fue el pino carrasco (RodrígueZ, 1996) que, junto con el álamo blanco o peralejo, se comportan como especies-guía ${ }^{3}$ de la carpintería nazarí de la Alhambra, en el periodo de esplendor de Yusuf I y Muhammad V. Por el contrario, la presencia minoritaria o ausencia de pino laricio o silvestre indican una caída o pérdida de las vías de aprovechamiento de estas especies, en el mismo momento en que se mantenía un activo comercio de cedro con el Magreb.

La denominación "pino de Segura» aparece con regularidad en crónicas y contratos de obras de toda Andalucía a partir del siglo XV. Con la conquista de Granada el pino laricio de Cazorla y Segura se utiliza en la Alhambra traído en carretas para la restauración de las Casas Reales en 1497 (Malpica y BermúdeZ, 2003). De este modo termina la escasez y carestía de la madera del periodo nazarí y se empieza a utilizar en la arquitectura morisca del XVI de Granada un excelente material traído de los pinares de Huéscar y Segura (GÓMEZ-MORENO, 2001). Hemos encontrado esta madera y datado en 1513 post quem (figura 4) las primeras restauraciones cristianas que se realizaron en el siglo XVI en las armaduras del Partal (Rodríguez, 1996). A partir de este momento, el pino laricio desempeña la función de especie-guia de las numerosas restauraciones que se realizarán en el siglo XVI y posteriores en el conjunto de la Alhambra.

Por el contrario, en edificios plenomedievales de la cuenca del Duero no consta el uso de madera de pino laricio y es el pino silvestre quien ocupa su lugar, junto a

\footnotetext{
${ }^{3}$ Utilizamos aquí el término especie-guía con un significado análogo al que se da a fósil-guía, fósil-director o fósil-tipo en la literatura arqueológica. El uso de varias especies o tipos de madera puede aparecer circunscrito a un periodo y contexto determinados y puede operar, por tanto, como indicador cronológico. No obstante, consideramos que esta función debe estar integrada en un sistema interpretativo de múltiples indicadores (CABALLERO, 2004).
} 
otras coníferas más locales, como el pino pinaster o la sabina. Un caso representativo es el alfarje del claustro bajo del Monasterio de Silos que tras su incendio en 1384 se reconstruye con madera de silvestre dendrodatado entre 1389 y 1391 (figura 4; RodríguEZ, en estudio). También en 1444 se construía la techumbre de la próxima iglesia de Caltojar (Soria) utilizando maderas de pino silvestre y pinaster. Pese a la presencia en la misma región de alguna formación de pino laricio, estas masas debían tener ya carácter relícto (SANTIAGO, 1995) y, por el momento, no se ha hallado esta especie en las construcciones de la época.

\section{CONTINUIDAD Y DIVERSIDAD DE PROCEDENCIAS}

El aprovechamiento de las Sierras Béticas fue posible al disponer de la vía del Guadalquivir. Si bien su navegabilidad se encontraba limitada hasta Córdoba, el transporte de madera desde la Sierra de Segura se mantuvo en todo el medievo, en buena medida impulsado por la demanda de las sucesivas atarazanas de Sevilla, las de Abd al-Rahamman II, las almóhades y las construidas por Alfonso X en 1252, que tendrán una actividad intermitente hasta el siglo XVI (COLlantes De Terán, 2001). En Sevilla, año 1587, Alonso de Morgado describe «...los grandes pinos labrados de las sierras de Veas y de Segura que por el río abaixo los traen en balsas hombres,...». Una imagen de esta actividad se nos muestra en los dibujos de Antón van der Wyngaerde (1567), que detalla los apilamientos de maderos a orillas del río y cerca de las atarazanas (KAGAN, 1986). El mismo artista dibujó en 1565 el saque de madera del Júcar en la ciudad de Cuenca (figura 5) y en 1563 una vista de Toledo, en la que se aprecian también maderos apilados a orillas del Tajo (ІВÁNEZ, 2003). Esta localización nos remite a las maderadas de pino laricio que bajaban por el Tajo desde la Serranía de Cuenca con destino a los edificios en construcción de la Corte, entre los que se incluye la iglesia de San Jerónimo en Madrid (dendrodatada en 1505) y el Monasterio del Escorial, tal como describe José de Sigüenza (1600): «... Los pinares de Cuenca, Balsain de Segovia, Quejigal de Avila y de las Navas...». Es decir, se utilizaron en la construcción tanto madera de pino laricio de Cuenca como pino silvestre de la región circundante. En los siglos siguientes el principal descargadero de la madera de laricio que descendía por el Tajo se trasladará de Toledo a Aranjuez para mejor abastecer a la Corte (PiQUeRAS y SANChÍs, 2001).

\footnotetext{
${ }^{4}$ Los nombres que en el siglo XVI recibía el pino laricio en diferentes regiones, tal como se citan en las «Relaciones» de Felipe II, no difieren de los actuales: pino negral en la Serranía de Cuenca (ARROYo, 1998) y pino salgareño en la villa de Segura (LóPEZ, 1999). En ambas regiones se nombran también 3 especies de pinos: carrasco ( $P$. halepensis), rodeno (P. pinaster) y doncel $(P$. pinea).
}

En los siglos XV y XVI estaba plenamente desarrollado en Sevilla el comercio por vía marítima de maderas que procedían de Galicia (CARLE, 1976) o que eran traídas por barcos ingleses, bretones y flamencos que fondeaban en los puertos de Moguer, Palos y Huelva (GONZÁLEZ, 1984). Este abastecimiento consistía, principalmente, en madera de "pino de Flandes» y de borne, denominación esta última que se aplicó al roble importado de Europa. A partir del siglo XVI, en los contratos de carpintería de iglesias y retablos de toda Andalucía, se suele especificar el uso de borne y pino de Flandes, junto con el pino de Segura y algunas más como álamo, castaño, nogal y cedro (LÓPEZ MarTínEZ, 1929; CANDELAS, 2001). Esta última madera hay que relacionarla con las que llegaban de las Indias y recibían la denominación genérica de cedro al presentar alguna cualidad aromática. El abastecimiento de pino de Segura se reactivó con motivo de la construcción de la Fábrica de Tabacos en Sevilla creándose en 1733 el Real Negociado de Maderas del Segura que monopolizará su comercio hasta el año 1817, en que fue traspasada su jurisdicción a la Real Hacienda de Marina (CRUZ AgUilar, 1987).

El uso de una denominación geográfica para cada clase de madera introduce cierta confusión en su identificación. Así, por ejemplo, el pino de Segura no puede tomarse como equivalente de pino laricio, puesto que el mismo nombre podrían recibir otras especies procedentes del alto Guadalquivir, como los pinos pinaster y carrasco 5 . Además, las denominaciones: pino de Segura (laricio) y pino de Flandes (silvestre), nos plantean una vez más el problema de la diferenciación de las dos especies. Hay que indicar que esto no es una cuestión secundaria, pues la procedencia condiciona la dendrodatación de manera que se necesita utilizar las cronologías de referencia específicas para cada especie y región de origen de la madera. Lo mismo es aplicable a la madera de roble, sobre todo en Andalucía y a partir del siglo XV, con el problema de diferenciar entre el roble andaluz o quejigo (Quercus faginea) y el borne, que es un roble europeo (Quercus robur L. / Q. petraea (Mattuschka) Liebl.).

En los siglos XVII y XVIII, el uso de madera de laricio y silvestre estaba plenamente extendido en toda Andalucía. Se constata su utilización en obras carpinteras de calidad, como el techo del coro de la Iglesia de Santa Clara de Córdoba, dendrodatado en 1798; o la nueva armadura que

\footnotetext{
${ }^{5}$ Por completar las denominaciones históricas del pino laricio en el siglo XVIII, recogemos la denominación pino blanco que se usa en el inventario de Spelius de 1765 de la provincia marítima de Segura (GÓmEz CrUZ, 1991), que coexiste con la de pino salgareño que se da en otros conteos (LÓPEZ, 1999).
} 


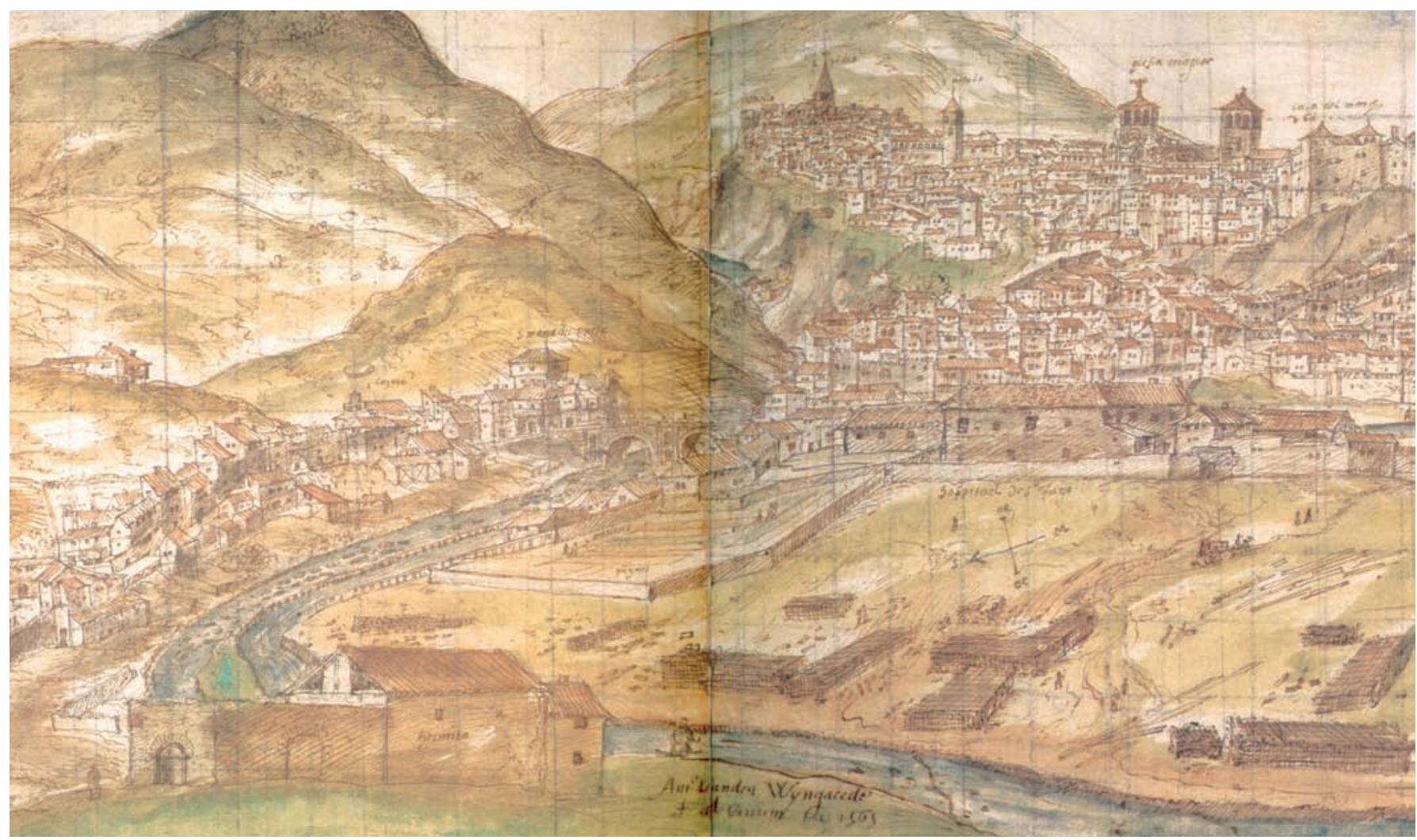

Fig. 5. Vista de Cuenca desde el oeste (1565) de van den Wyngaerde. Capta el descenso de maderadas por el Júcar y su saca en el desaguador de Haza de Santiago en donde se apilaba la madera en peañas para secarla antes de ser vendida. (Tomado de IBÁÑEZ, 2003)

se construye en 1755 en el Cuarto Real de Santo Domingo de Granada. Destaca la calidad de estas maderas con secuencias de anillos que superan los 200 años y su alto contenido en resina, lo que les confiere una extraordinaria dureza y resistencia a la degradación. Sin duda, el uso tradicional de pino laricio se mantuvo a lo largo del siglo XIX, tal como se constata en la restauración de Rafael Contreras de las cubiertas de la Sala de los Reyes de la Alhambra (dendrodatadas en 1855).

A partir de la mitad del siglo XVIII, la Marina desarrolló una intensa explotación de la Sierra de Segura para abastecer los arsenales de la Carraca (Cádiz) y de Cartagena. Se utilizaron dos vías de saca de la madera: por los ríos Guadalimar y Guadalquivir hasta Sevilla, y por el río Segura hasta su desembocadura en Guardamar de Segura (ARANDA, 1990). En el mismo periodo los pinares de laricio de la Serranía de Cuenca estaban sometidos también a una intensa explotación y se realizaba una doble saca, una hacia el oeste por el Tajo y otra hacía Valencia por los ríos Curiel y Júcar. Una tercera saca más al norte utilizaba el Guadalaviar-Turia, si bien por este río descendía sobre todo madera de pino silvestre (GIL, 2006). De este modo, en el abastecimiento de madera de la región levantina aparecen una vez más mezcladas las maderas de silvestre y laricio, planteándonos de nuevo el problema de su diferenciación ${ }^{6}$.

\section{DOS ÁREAS DE APROVECHAMIENTO EN EL PRIMER MILENIO}

Lo hasta aquí expuesto es suficiente para ilustrar el amplio uso que ha alcanzado la madera de pino silvestre/laricio en los últimos diez siglos en nuestro país. Podemos remontarnos ahora a un periodo anterior, en el que posiblemente la madera de estas especies no estaría sometida a tan alto nivel de explotación, lo cual no significa que no fuera objeto de un activo aprovechamiento y no se valorase ya como un buen material de construcción. El mismo hecho de su conservación durante tantos siglos, sin apenas merma de sus cualidades, viene a justificar esa valoración.

\footnotetext{
${ }^{6}$ Otra vía de abastecimiento de madera a Valencia y otras grandes poblaciones, como Zaragoza y Barcelona, era el río Ebro, sus grandes afluentes pirenaicos (Aragón, Gállego y Segre) y los afluentes de éstos (Iratí, Cinca, Noguera Ribagorzana, Noguera Pallaresa, etc.) (PIQUERAS Y SANCHÍs, 2001). El descenso de madera se realizó tradicionalmente mediante armadías en lugar de las habituales maderadas libres de las otras cuencas. En estas sacas de madera, el pino silvestre era más frecuente que el pino laricio, junto a otras especies como abetos, hayas, fresnos, álamos, tilos, etc., que formaban parte también de estas armadías (GIL, 2006).
} 
Debemos destacar que en los edificios altomedievales de Toledo que hemos podido estudiar (Torre del Salvador, Puertas de Bisagra, etc.) se utiliza madera de pino pinaster (RodRÍGUEZ, 2006), pero no se encuentra madera de silvestre/laricio, pese a su posible aprovechamiento en la Sierra de Gredos o conducida por el Tajo desde la Serranía de Cuenca. Los edificios con restos lígneos de silvestre o laricio se localizan en dos regiones distintas y alejadas entre sí, aunque asociadas a las cuencas medias de dos grandes ríos peninsulares, el Guadalquivir y el Duero. Este conjunto de enclaves con madera de pino ha permitido elaborar varias cronologías que cubren casi por completo el primer milenio.

\section{La vía fluvial del Guadalquivir}

La Mezquita Aljama de Córdoba es un edificio singular cuya historia constructiva supera los dos siglos: iniciada por Abderramán I en el 784, fue objeto de sucesivas ampliaciones hasta la última realizada por Almanzor en el 988. No consta que en las distintas remodelaciones se produjese un cambio de la tipología de su techumbre, por lo que ésta fue siempre plana y según Félix Hernández (1928) con una estructura muy simple de vigas transversales a las naves y tableros sobrepuestos (figura 6). Este autor realiza el primer estudio sistemático de la techumbre a partir de las vigas y tablazón conservadas, en su mayoría procedentes de las naves que en 1723 se abovedaron desmontando la vieja techumbre que tenía muchas vigas con sus entregas podridas. Buena parte de estos elementos se reutilizaron como pares de la cubierta de las mismas naves restauradas. Según Hernández (1928), el maderamen conservado perteneció a la gran ampliación que realizó al-Hakan II entre 962 y 965, datación que ha sido compartida, entre otros, por Gómez Moreno (1932) y Torres Balbás (1957).

Se encuentra en fase de estudio un amplio grupo de vigas y tablas con diferentes escuadrías, longitudes de labras, decoraciones, etc., que tiene por objetivo discriminar posibles etapas de construcción de las sucesivas ampliaciones. Otro aspecto importante es llegar a determinar la ubicación en distintas naves en función de las longitudes de labra y total de cada viga. Por el momento, se han interdatado vigas y tableros entre sí, lo que demuestra que son elementos de una misma etapa constructiva. Incluso se han obtenido grupos de piezas procedentes de un mismo rodal (figura 7). A partir de este material se ha elaborado una cronología de 378 años, cuyo final ha sido datado por carbono-14 en 946-1086 cal $A D$, compatible con las dos últimas ampliaciones de la mezquita, las correspondientes a al-Hakan II (962965) y a Almanzor (987-978).

Una cuestión clave ha sido la identificación exhaustiva del material con el objetivo de determinar su origen geográfico. Toda la madera ha sido identificada como pino laricio a partir de la proporción albura/duramen observada y con el apoyo en otros caracteres como altas textura y sensibilidad, crecimientos mínimos y largas secuencias, así como alto contenido de resina. Nuestra interpretación inmediata ha sido suponer que esta madera procedía de las Sierras de Segura y Cazorla y que habría sido transportada en maderadas por el Guadalquivir. Este río ya era navegable hasta Cástulo (Linares) desde el siglo I a. C., lo que favoreció la explotación minera y el transporte de productos agrícolas y forestales (BLÁZZUEZ, 1996). En el siglo X, según Ibn Hayyan relata en los Anales Palatinos de alHakam, se explotaba activamente la madera del alto Guadalquivir, y al-Zuhri da cuenta de los problemas de su transporte, que debía realizarse en su tramo inicial por el Guadalimar, del mismo modo que se seguirá haciendo hasta el siglo XVIII (cit. LÓPEZ, 1999).

Sin embargo, en 1154 el geógrafo al-Idrisi describe la techumbre de la Mezquita que contempla in situ y, en su explicación sobre la madera, se refiere a los pinos traídos de Tortosa (al-sanawbar al-turtusi). Es sorprendente que alIdrisi desconociera la vía fluvial del alto Guadalquivir y qué fuente pudo utilizar para afirmar dicha procedencia. Sin duda conoció bien las atarazanas de Tortosa, construidas por Abderraman III en el 913, y sus zonas de abastecimiento en los pinares de Beceite y en el Maestrazgo, además de la pinadas bajadas por el Ebro desde el Pirineo central. Debemos indicar que este origen alternativo no afectaría a la identidad de la especie, pues podría tratarse igualmente de pino laricio. Autores cualificados como Hernández (1928) y Gómez Moreno (1932) han aceptado la explicación del geógrafo árabe, mientras Torres Balbás (1957), aunque valorando el excelente pino utilizado, no llegó a pronunciarse sobre su origen.

Con todo, el verdadero problema de identificación de la madera de la techumbre, se inicia con Ambrosio Morales (1575) en su descripción de la techumbre: «La madera es toda de alerze, y es como pino, mas muy oloroso, que solamente lo ay en Berueria, y desde alla se truxo por la mar y las vezes que han derribado algo de la iglesia, para nuevos edificios ha valido muchos millares de ducados la madera de despojo, para hazer vihuelas y otras cosas delicadas.». Es oportuno puntualizar que estas primeras referencias nada tienen que ver con la madera de Larix decidua Miller, una conífera foránea que recibe hoy en castellano el nombre 


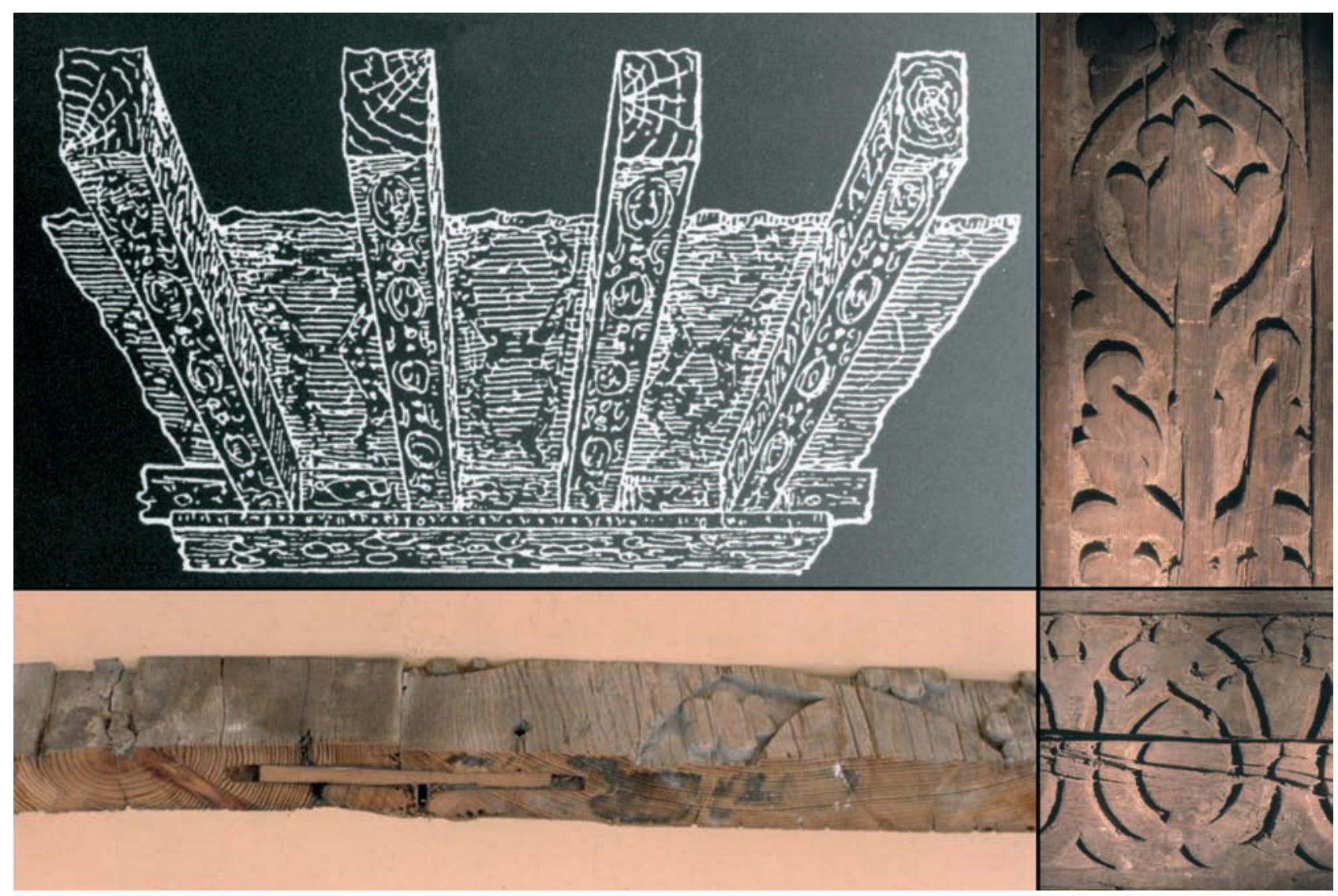

Fig. 6. Reconstrucción de Félix Hernández (1928) de la techumbre de la Aljama de Córdoba. Las vigas eran enterizas y las tablas se unían a media madera con espigas. La decoración de las vigas cubría tres caras, pero ha sido necesario recomponer su decoración lateral pues la mayoría se cortaron al ser reutilizadas en el siglo xvill

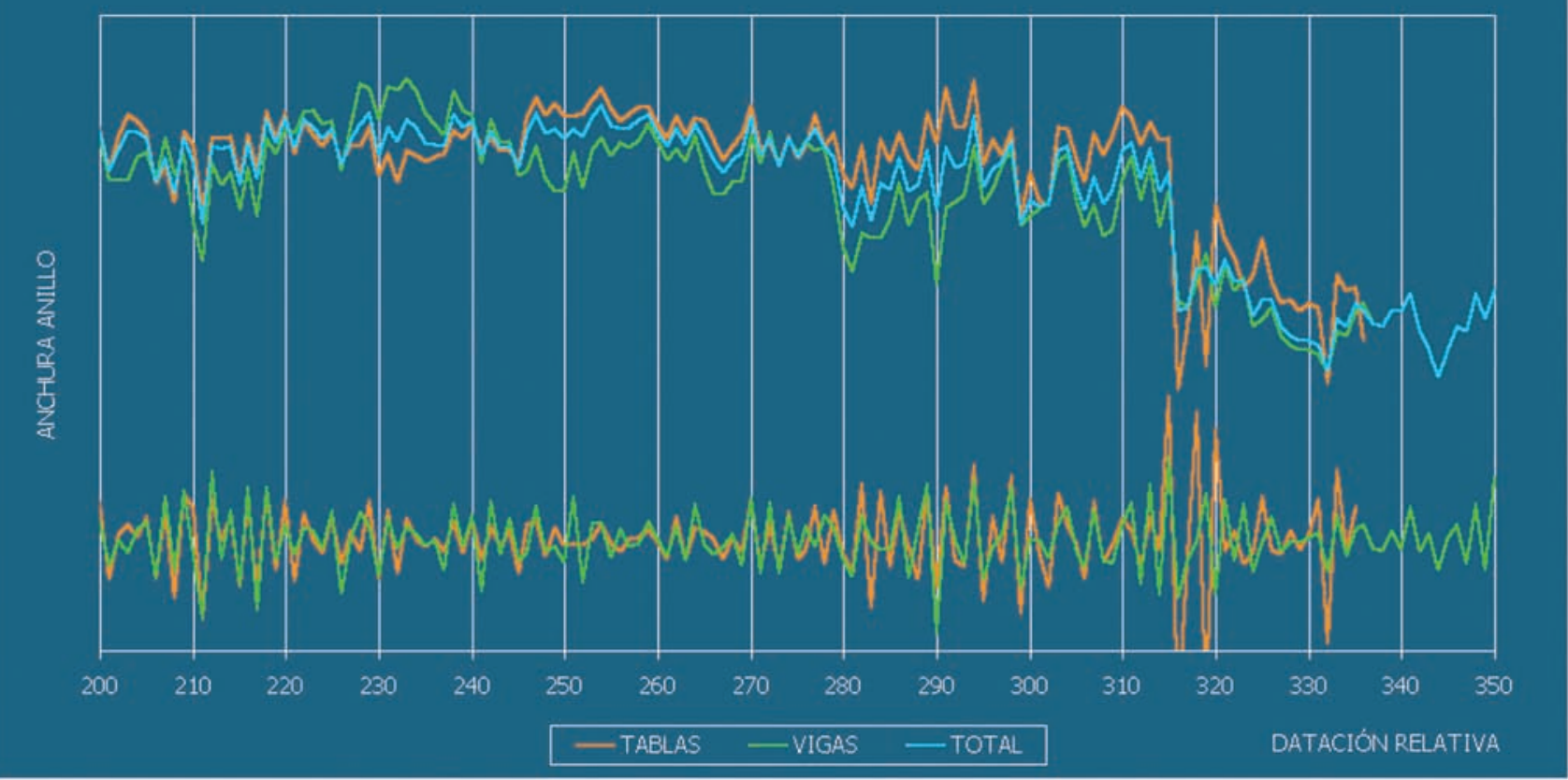

Fig. 7. Techumbre de la Aljama de Córdoba. Interdatación de tablas y vigas ( $t=7,68$, intervalo: 217 años) que muestra que ambos tipos de elementos fueron aprovechados en una misma masa forestal. Arriba: valores brutos / Abajo: filtrado interanual 
común alerce. El origen de este equívoco está en el error que introdujo Andrés de Laguna en 1555 al resaltar el parecido entre las voces alerze y lárice, siendo esta última el verdadero nombre castellano que recibía Larix decidua en la época. La amplia difusión y autoridad de la obra de Laguna hizo que se fijara este cambio de nombre (FERNÁNDEZ, 1996), desplazando la voz lárice que, no obstante, todavía es recogida por el D.R.A.E. Hay que precisar que el origen etimológico de ambos términos es diferente, pues mientras lárice es de origen latino, la voz alerce deriva del término árabe al-arz (CARABAZA et al., 2004). Según estos autores, la mayoría de los tratadistas andalusíes identificaban arz con el cedro, si bien algunos lo aplicaban también al enebro ('a'ar) e incluso al ciprés (sarw) y a la variedad masculina o infecunda del pino (sanawbar).

Esta digresión etimológica está justificada, pues el término alerce arrastra históricamente un significado genérico y algo confuso que podría deberse al carácter aromático e imputrescible que tienen todas las maderas a las que se ha aplicado ${ }^{7}$. Son precisamente estas propiedades extraordinarias las que han motivado la proliferación de asignaciones de la madera de alerce a obras de calidad y magnas construcciones a partir del siglo XVI y hasta nuestros días (FERNÁNDEZ, 1996). Entre ellas debemos incluir la realizada por Ambrosio de Morales en 1575, que será secundada por autores posteriores, algunos de los cuales tuvieron en sus manos la madera, como el obispo Gómez Bravo (1723) que promovió la sustitución de la techumbre por bóvedas encamonadas. Una identificación diferente realizó Hermosilla en 1767 (cit. RODRÍGUEZ, 1992) que refiere: reconoci con mucha prolixidad estta madera, y hallé que es pinabette, y ciprés. En la misma línea se expresaron viajeros y eruditos del siglo XIX, como Girault de Prangey, en 1833, que describe el alerce como especie entre el cedro y el pino -el Pinus larix. Asimismo Richard Ford (1845) habla de L'aris de Berbería y Ramírez y de las Casas-Deza (1853) identifica la madera de la techumbre como alerce africano (Tetraclinis articulata), siguiendo la teoría formulada por el botánico Colmeiro (véase nota 7).

Finalmente, algunos autores del XIX se han referido a la tradición que sostenía que en la construcción de la techumbre se utilizaron pequeñas masas de "pinos alerces» que crecían en la campiña cordobesa. En apoyo de esta

${ }^{7}$ El carácter confuso y equívoco del término alerce llevó a acepciones poco afortunadas que introdujeron algunos botánicos del siglo XIX. Así, Colmeriro sostuvo que el alerce era realmente el arar del norte de Marruecos (Tetraclinis articulata), al que propuso denominar alerce africano, para diferenciarlo del alerce europeo (Larix decidua). Por su parte, WillKomm y Lange utilizaron el nombre alerce español para denominar al enebro de la miera o cada (Juniperus oxycedrus L.). hipótesis, se ha citado la crónica anónima árabe del s. XI que alude a un bosquecillo de arz que en el s. VIII estaba situado cerca de la alquería de Xecunda, en la margen contraria del río frente a Córdoba (cit. FERNÁNDEZ, 1996). Es evidente que no es un emplazamiento verosímil para una formación natural de cedro o pino laricio; si bien la consideración del alerce como clase de pino se acerca, en cierto modo, a la verdadera identificación de la madera.

\section{La conexión Pino-Duero}

\section{Un material lígneo singular}

El desmonte y traslado de la iglesia de S. Pedro de La Nave (Zamora) realizados en 1931-32 permitió recuperar un elemento estructural de gran escuadría que actualmente se encuentra depositado en el Museo de Zamora. Se trata de una viga de pino ( $278 \times 38 \times 28 \mathrm{~cm})$, que presenta en una cara menor cuatro cajas con forma de cola de milano. Estaba situada en el muro de testero de la nave del anteábside, dispuesta sobre el arco del triunfo y encadenada a tres sillares por grapas de madera (figura 8). En otros edificios distantes de La Nave, pero situados en la cuenca del Duero, se han hallado también grandes elementos de madera de pino. Así, en la iglesia de $S$. Juan de Baños (Palencia) se han hallado 3 vigas (figura 8) y en Burgos se han localizado y se estudian también dos construcciones singulares que conservan grandes maderos de pino. Nos referimos a los restos de la iglesia de Quintanilla de las Viñas y a la iglesia de Santa Cecilia de Barriosuso (figura 8).

En todas estas construcciones se utilizó madera de pino silvestre o de laricio, cuya diferenciación no ha sido posible a partir de los caracteres de los elementos conservados y que, por tanto, nos plantea de inmediato la doble cuestión de su identificación y procedencia geográfica, habida cuenta de las distancias que median entre estas construcciones y las masas actuales de pino silvestre o laricio. Por una parte, diferentes registros polínicos y de macrorrestos confirman el carácter autóctono tanto del pino silvestre como del pino laricio en el borde e interior de la Meseta norte (GARCíA ANTÓN et al., 1997; SÁNCHEZ HERNANDO et al., 1999). Un especial interés tienen los depositos en depresiones interiores como la cercana a Espinosa de Cerrato, en la que se ha registrado polen de Pinus sylvestris-tp dominante entre 4000 y 3000 BP (Franco Múgica et al., 1996). Asimismo los depósitos de piñas y maderas próximos a Cevico Navero $(840$ $\mathrm{m}$ de altitud), cuya edad carbono-14 es $4650 \pm 60 \mathrm{BP}$, han sido identificados como pino laricio (RoIG et al., 1997). Hay que destacar que estos depósitos se encuen- 


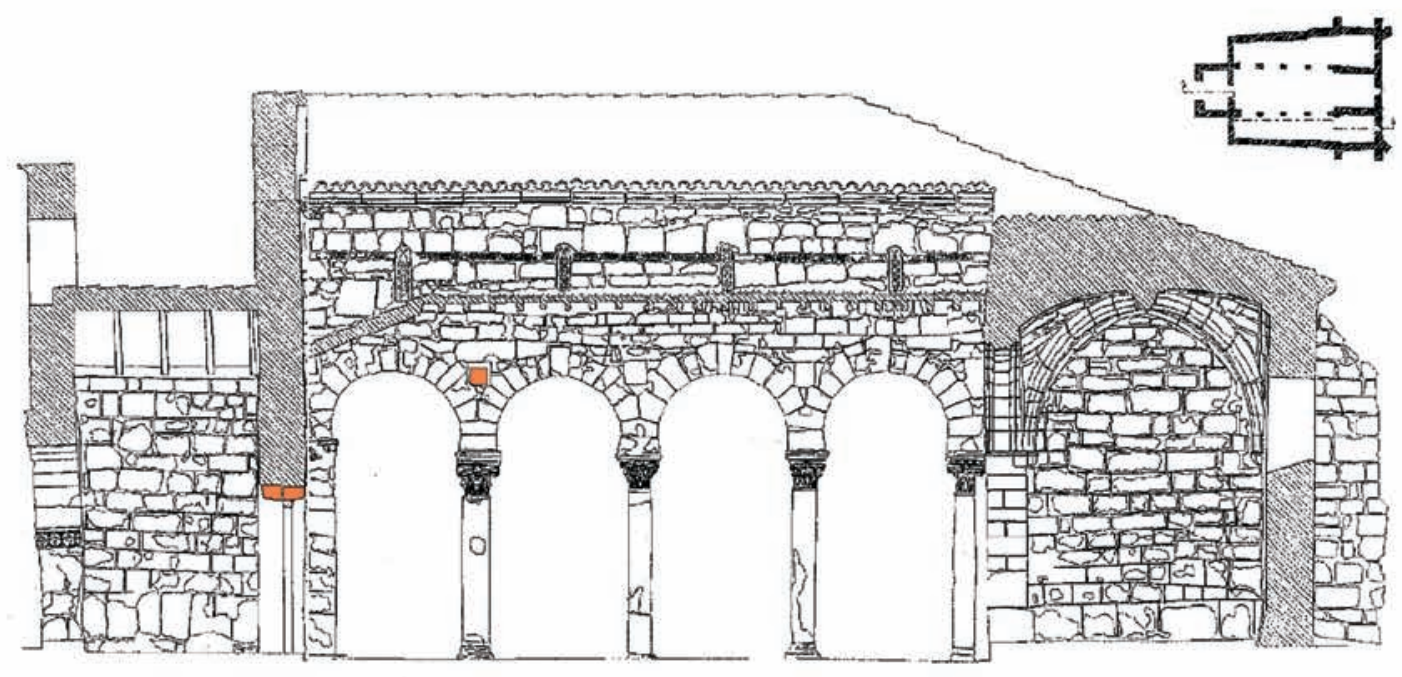

S. JUAN DE BAÑOS (PALENCIA)

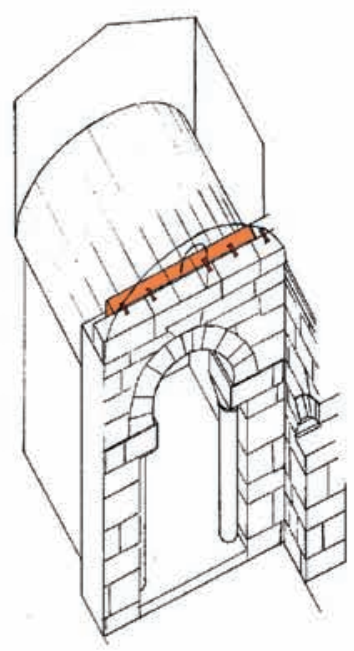

S. PEDRO DE LA NAVE (ZAMORA)

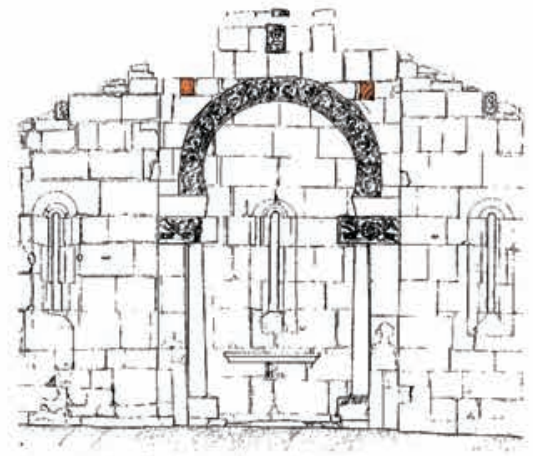

QUINTANILLA DE LAS VIÑAS (BURGOS)

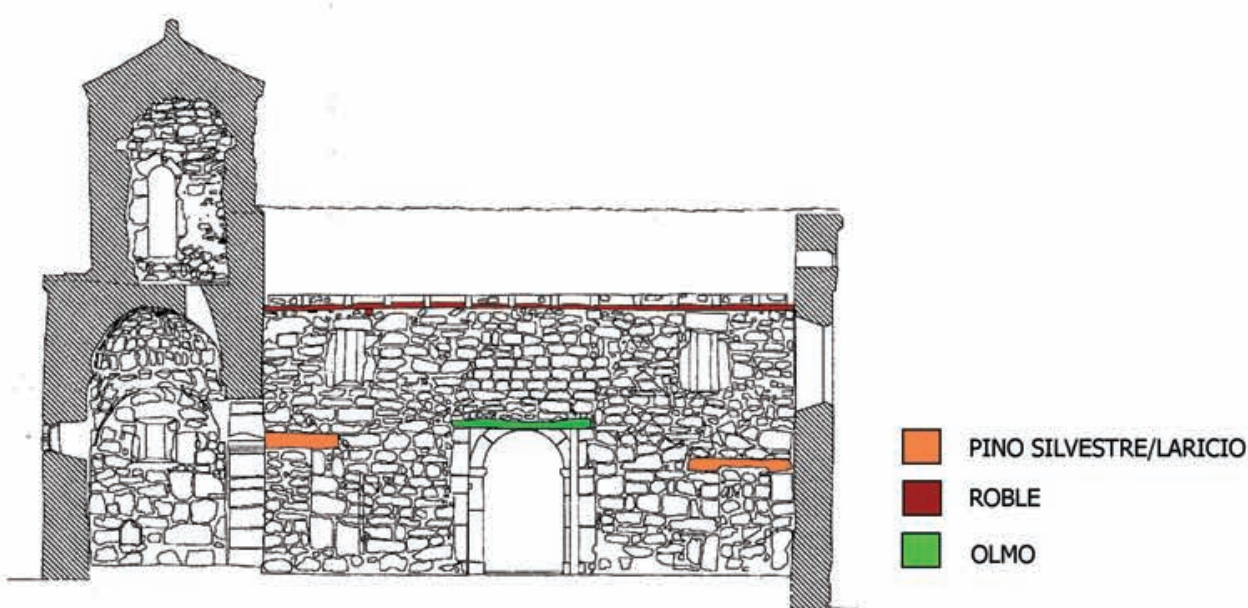

STA. CECILIA DE BARRIOSUSO (BURGOS)

Fig. 8. Localización de los elementos lígneos estudiados en iglesias de la cuenca media del Duero. Tomado de: Baños (CABALLERO y FEIJOO, 1998), La Nave (Alonso et al., 2004), Quintanilla (ARBEITER, 2001) y Barriosuso (sección de CABALLERo ZoREDA et al.) 
tran por debajo de los $1000 \mathrm{~m}$ de altitud y que las piñas indican una localización próxima dentro de la misma comarca, a diferencia del polen de pino que tiene una dispersión regional. La proximidad de estos restos, a tan sólo $20 \mathrm{~km}$ de Baños, fundamenta la hipótesis de que la viga encontrada en San Juan de Baños sea realmente pino laricio.

Las dos iglesias burgalesas, Quintanilla y Barriosuso, se localizan en las proximidades de la Sierra de la Demanda, donde actualmente el pino silvestre forma importantes masas, pero también con algún enclave relíctico de Pinus nigra, como el de la garganta del río Lobos (SANTIAGO, 1995). Asimismo en el valle del Arlanza, existen fondos de valle con turberas fósiles donde se han recogido piñas de tamaño intermedio entre pino silvestre y laricio (ORIA DE RUEDA, 1996). Otros hallazgos confirman el origen autóctono del pino silvestre y/o laricio y la relativa importancia que debieron alcanzar sus masas en la cuenca del Duero. Así, en yacimientos de la Segunda Edad del Hierro situados en la cuenca media se han identificado como pino silvestre carbones de hornos (yacimientos de Pesquera y Padilla de Duero) y un poste de cabaña del poblado vacceo de Soto de Medinilla (UzQUiAno, 1995); todos ellos datados entre los siglos III y I a. C. (EsCUDERO, 1995; SANZ y ESCUDERO, 1995). Como hemos indicado repetidamente, la identificación anatómica de madera no pueden discriminar son seguridad entre las dos especies de pino.

A más de $200 \mathrm{~km}$ al oeste del grupo de iglesias anterior, se localiza San Pedro de la Nave en la comarca zamorana de Aliste, en un entorno natural de transición entre el dominio mediterráneo y el euroatlántico y sobre una litología silícea que contrasta con la caliza de Baños y el resto de iglesias. En este entorno es extraño que se utilizara madera de pino para labrar la gran viga en lugar de madera de roble tan abundante en la región. Hay testimonios de la existencia a principios del siglo XX de gruesos tocones de pino en las umbrías de la próxima Sierra de la Culebra; que serían probablemente de pino silvestre, a juzgar por el duro régimen de heladas que afecta a esta sierra (RUIZ DE LA TORRE, 1991). Asimismo los registros paleobotánicos confirman la presencia de Pinus sylvestris-tp en depósitos turbosos de la Sierra de la Culebra (MuÑoz Sobrino, 2001) y se ha constatado la persistencia de formaciones forestales en la región, de modo que el ascenso del polen de cereal respecto al arbóreo no se produjo hasta $1250 \pm 25 \mathrm{BP}$ (MuÑOZ et al., 1997). Actualmente no se conservan masas relictas de pino silvestre en la zona y las masas naturales más próximas son el bosque de
Puebla de Lillo (León), en la cabecera del río Porma, y la pequeña masa de silvestre y laricio en Lastras de Cuellar, en los márgenes del río Cega, formando parte ya de niveles basales del Sistema Central.

Los datos anteriores avalan la hipótesis del carácter autóctono de todas estas maderas, así como la posibilidad de que fueran aprovechadas en entornos no alejados de los respectivos edificios en construcción. Sin embargo, si se tiene en cuenta el contraste bioclimático y edáfico en dirección este-oeste dentro de la cuenca del Duero, lo plausible sería considerar que el pino silvestre es más propio del entorno de La Nave, mientras que la presencia de pino laricio estaría más fundada en el grupo oriental. Surge, por tanto, como primera cuestión, si este grupo de maderas está integrado por una o dos especies. Lo cierto es que todos estos elementos lígneos proceden de árboles longevos y comparten los mismos caracteres ecofactuales. La viga de La Nave tiene 300 años, y los elementos de Baños entre 250 y 350 años. Las dos vigas de Barriosuso, 164 y 232, y las dos piezas de Quintanilla, 266 y 295 años. A estos valores debemos añadir los anillos perdidos por el labrado de las piezas, por lo que estimamos que casi todos los árboles superarían los 400 años de edad. Secuencias de anillos tan largas implican crecimientos muy pequeños y frecuentes anomalías de anillos ausentes. Se observan además otros rasgos de homogeneidad, como alto contenido de resina, fibra ondulada y gran nudosidad. Tal como indicamos anteriormente, son caracteres considerados más propios del pino laricio que del silvestre (figura 9).

Por otra parte, el análisis dendrocronológico ha mostrado una relación crono-espacial precisa entre la viga de La Nave y el grupo de Baños (AlONSO et al., 2004). Un primer resultado ha sido la datación relativa o interdatación de los elementos hallados en La Nave y Baños, que demuestra que la madera de La Nave es coetánea o posterior a la de Baños (en el supuesto de que se trate de la misma especie). En la figura 10 se muestra la alta similitud en que se basa la sincronización de las series E495001Z (viga de La Nave) y E3450020 (dintel oeste exterior de Baños). En la figura 11 se presenta el conjunto, situando la serie de La Nave (E495001Z) entre las dos series de Baños (E3450020/3Z) para comparar sus tendencias de crecimiento. Se han extrapolado las curvas de tendencia para indicar que las secuencias de anillos son incompletas debido al intenso labrado de las piezas. Las tres series están dispuestas en posición sincrona y se aprecia la coincidencia de ciclos de variación plurianual y la alta sensibilidad del crecimiento interanual. El nivel de similitud es tan signifi- 
Fig. 9. Tirante de S. Juan de Baños. Madera de pino con fuertes fluctuaciones en su secuencia de anillos y alto contenido de resina que indican condiciones limitantes del crecimiento

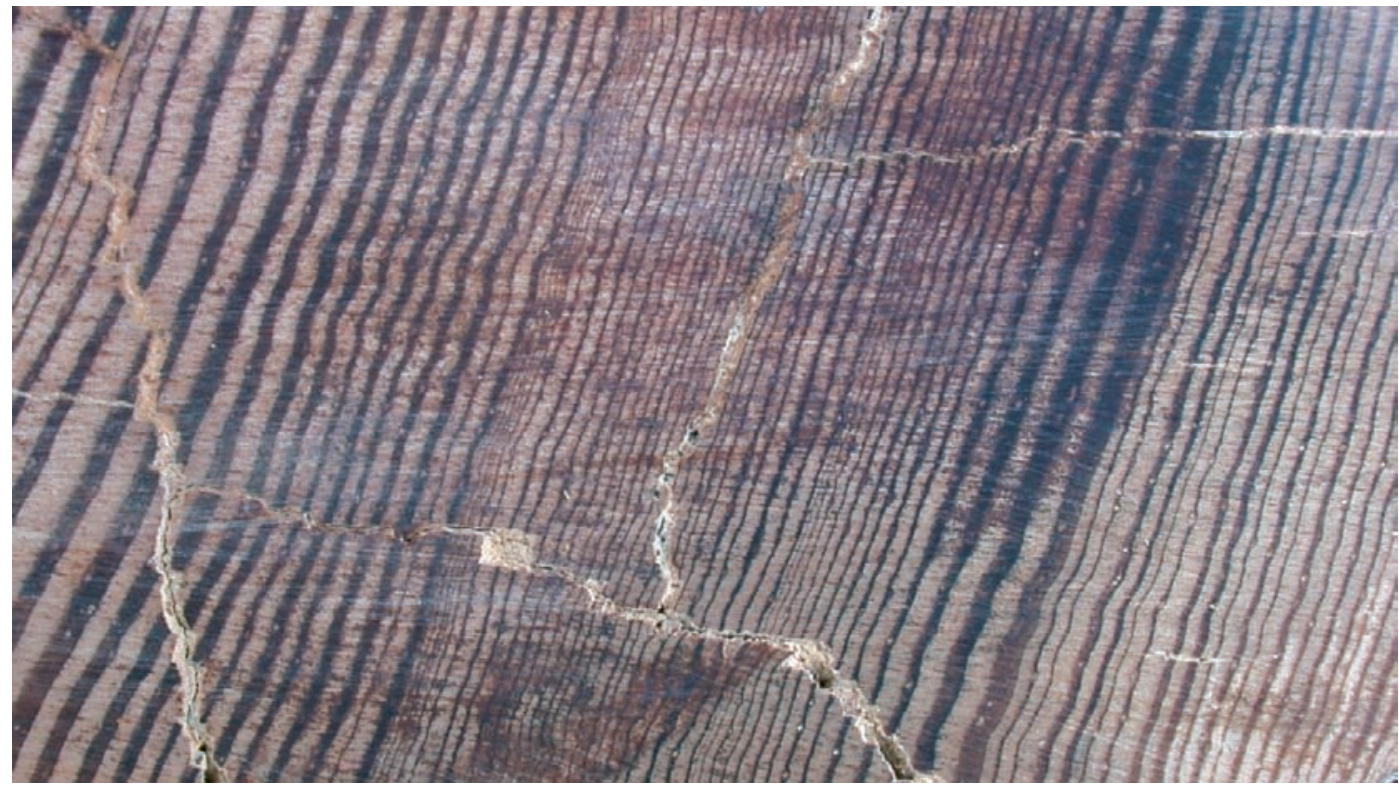

cativo que podemos afirmar que las maderas de La Nave y Baños proceden de una misma masa forestal o, cuando menos, tuvieron que crecer bajo condiciones microclimáticas parecidas. Este resultado sería todavía más notable en el supuesto de que las maderas de las dos iglesias pertenecieran realmente a especies diferentes. De este modo se nos plantea otra cuestión importante como es la procedencia del material, su posible origen común, así como las distancias y direcciones de las respectivas vías de transporte. A este respecto, desconocemos datos históricos sobre flotación de madera por el río Duero y sus grandes afluentes, que podrían explicar la conducción de madera desde las cabeceras de las cuencas.

Los resultados precedentes han permitido agrupar el material lígneo de La Nave y Baños en una única cronología de referencia. Se trata de una cronología flotante (Conexión Pino-Duero) que alcanza 401 años y suponemos construida con una única especie de pino que, en principio, nos parece más probable que sea pino laricio (Pinus nigra). Mediante la técnica wiggle matching de calibración de medidas carbono-14 de secuencias de estas maderas, se obtuvo la datación del último anillo de la cronología flotante en el intervalo 447-543 cal AD (99\%). Por el contrario, el material de Quintanilla de las Viñas y el de Santa Cecilia de Barriosuso no ha podido ser interdatado ni entre sí ni con el grupo anterior, por lo que se han datado separadamente por carbono-14 con la técnica wiggle matching (figura 12), resultando para el último anillo, respectivamente: $366-426$ cal AD (99\%) y 459509 cal AD (99\%).

\section{Las bases de una unidad eco-artefactual}

Una consideración global del material descrito nos lleva a reconocer que todos los árboles eran ejemplares añosos que crecieron en la primera mitad del primer milenio y se utilizaron en la construcción de una serie de edificios dispersos por la cuenca media del Duero. Tal como indicábamos, es oportuno preguntarse sobre la extensión geográfica de estas formaciones y su proximidad a cada edificio, o sobre si estos elementos procedían de viejas masas forestales o bien de pies aislados, afectos ya de cierto carácter relicto. Hay que tener en cuenta además que, tal vez con la excepción de Baños, no debieron faltar otros árboles de buen porte, como robles, sabinas, etc., en el entorno próximo a las iglesias. Todo ello nos permitiría calibrar la disponibilidad del material y por ende el grado de selección que operó en su aprovechamiento. En cualquier caso, parece evidente que la elección de una madera de tanta calidad fue plenamente intencionada, con independencia de la abundancia de este recurso a lo largo del periodo.

Por otra parte, cabe preguntarse si la homogeneidad ecofactual mostrada es en realidad una imagen distorsionada de una mayor variedad de maderas que se utilizaron en la construcción original y que llegaron a desaparecer por degradación. Este efecto de degradación diferencial puede contribuir a explicarnos la coincidencia de la misma especie en construcciones tan dispersas. Sin embargo, el tipo de madera que describimos no aparece en fases de cronología posterior de estas y otras construcciones de la región, de modo que las maderas utilizadas son siempre especies (pino, roble, sabina, etc.) que actualmente siguen 


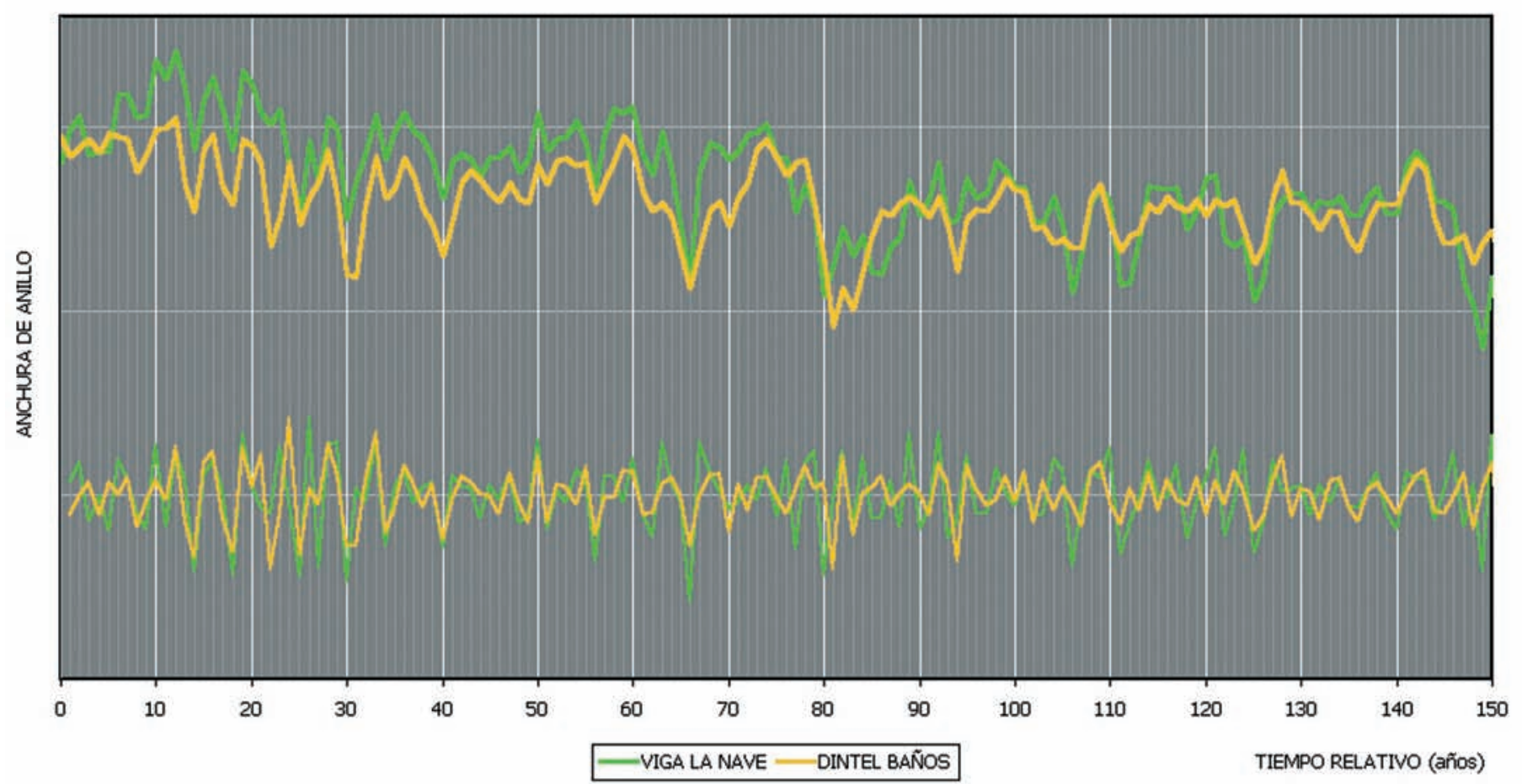

Fig. 10. Interdatación de la viga de S. Pedro de la Nave y el tirante de S. Juan de Baños. La sincronización es muy firme ( $t=10,94$, sobre intervalo de 293 anillos) y se basa en buena medida en la variación plurianual (arriba), cuya similitud es mayor que en la variación interanual (abajo)

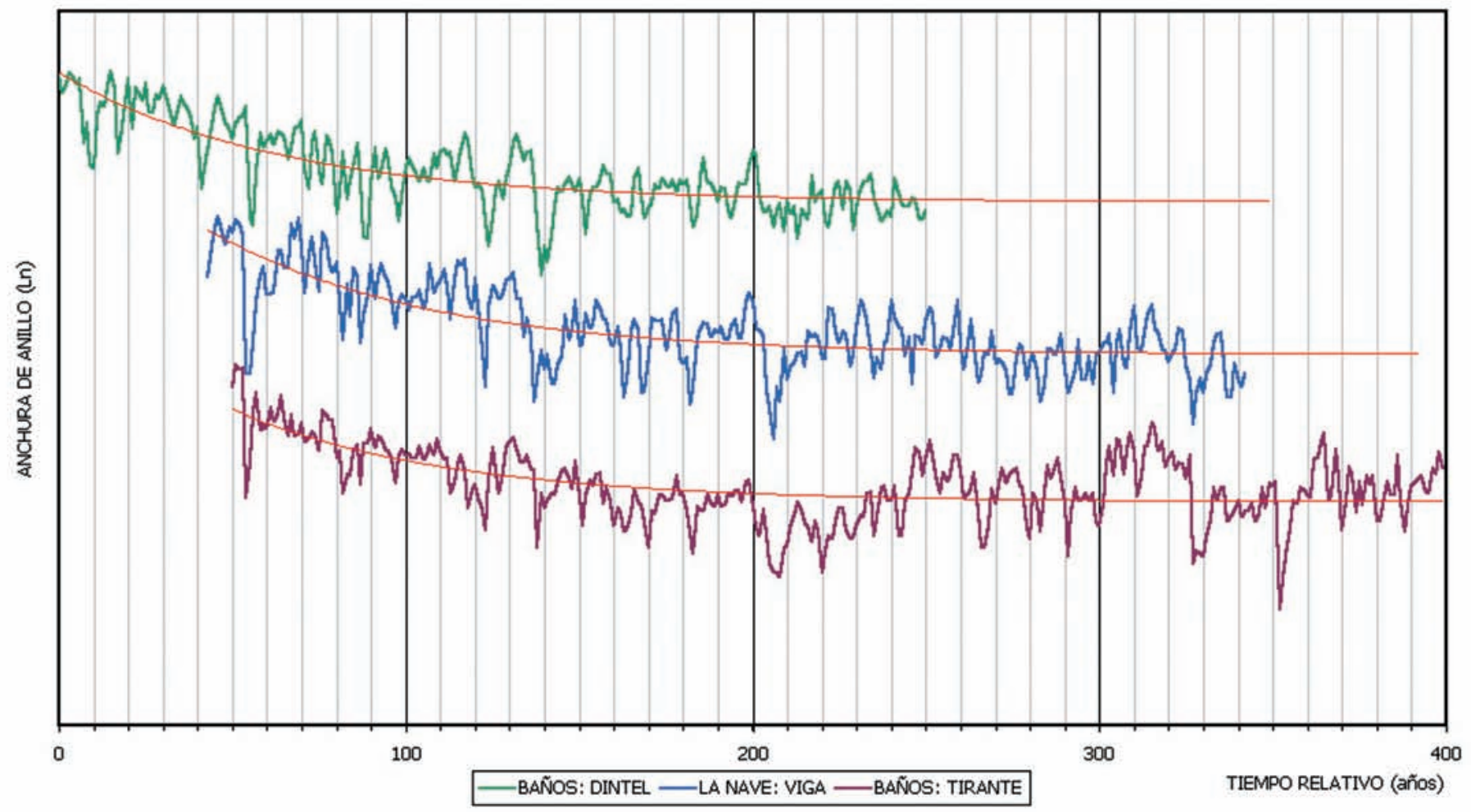

Fig. 11. Series completas de los elementos de La Nave y Baños en posición síncrona con sus ajustes de tendencia respectivos (en rojo). Las tres series muestran entre sí una similitud equivalente y la serie de La Nave tiene su «fecha de nacimiento» entre las dos de Baños 


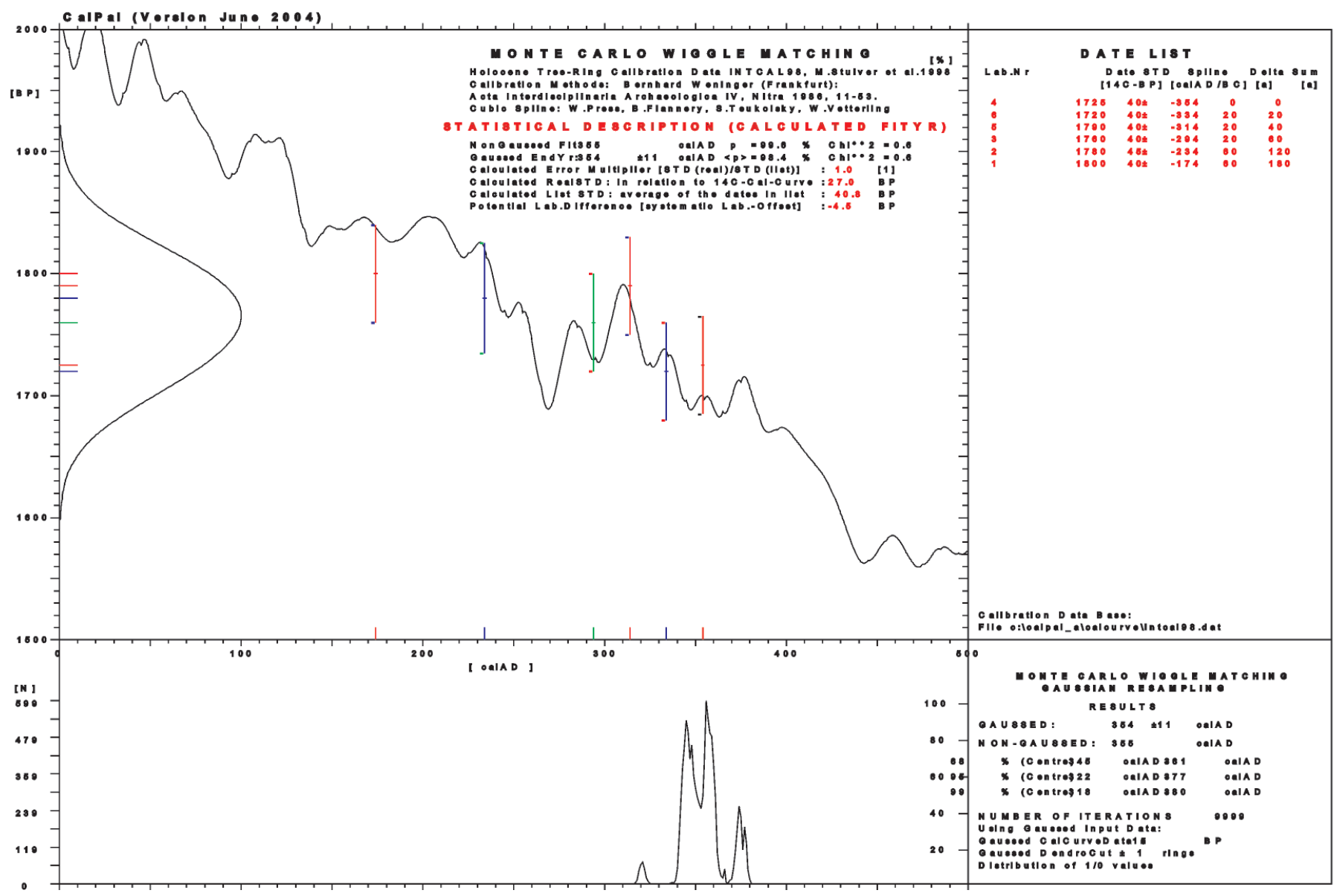

Fig. 12. Gráfico de calibración de una secuencia determinada (wiggle matching) de 6 muestras tomadas en la viga norte de Quintanilla de las Viñas que datan el último anillo en 366-426 cal AD (99\%). (programa GaussWM, WENINGER, 1997)

formando parte de la vegetación natural del entorno ${ }^{8}$. En consecuencia, los caracteres ecofactuales descritos permiten considerar a todo este material como especie-guía de un periodo de actividad edilicia en la cuenca norte del Duero, basándonos en la explotación selectiva de un recurso lígneo de calidad singular.

La determinación del periodo de aprovechamiento requiere de la estima de las edades de corte de los distintos elementos. Sin embargo, todas las piezas han perdido buena parte de su madera externa por causa del labrado y, por tanto, no podremos conocer con precisión las fechas de corte de los distintos elementos, ni tampoco se podrán ordenar cronológicamente. Además, sólo en una viga de Baños se observa el borde duramen-albura, por lo que en el resto de piezas habrá que añadir a la albura completa, la

\footnotetext{
${ }^{8}$ En Sta. Cecilia de Barriosuso se conservan un nudillo y parte del estribo de una armadura anterior a la actual que son de roble, cuya datación carbono-14 ha sido 685-805 AD post quem, coherente con la adscripción del edificio (CABALLERO, 1999). De un momento posterior (1406-1449 AD), es el cargadero de olmo utilizado en la reforma del nuevo acceso de arco de medio punto (figura 8).
}

porción perdida de duramen. Tal como hemos indicado, la estima de albura varía considerablemente según se trate de pino silvestre o laricio. Disponemos sólo de datos para árboles con menos de 300 años, y su extrapolación indica que en torno a los 300 años, la albura supera en promedio los 100 años en el pino silvestre y se duplica en el pino laricio. Por tanto, hemos optado por fijar una albura mínima de 110 como incremento a aplicar a las piezas, obteniendo la serie de fechas post quem siguiente: 476-536 cal AD (Quintanilla), 569-619 cal AD (Barriosuso), 499595 cal $A D$ (La Nave) y $499-595$ cal $A D$ (Baños). Es decir, las viejas masas forestales de pino silvestre/laricio fueron objeto de explotación posteriormente a 476 d. C., pero en 569 d. C. todavía seguía su aprovechamiento.

Por otra parte, es oportuno considerar también los aspectos artefactuales del material. Debemos reparar en la serie de caracteres comunes en cuanto a labra y funciones estructurales que se encomiendan a estos elementos. Así, el labrado es idéntico en todas las piezas, obteniéndose piezas enterizas, con médula centrada, y eliminando 


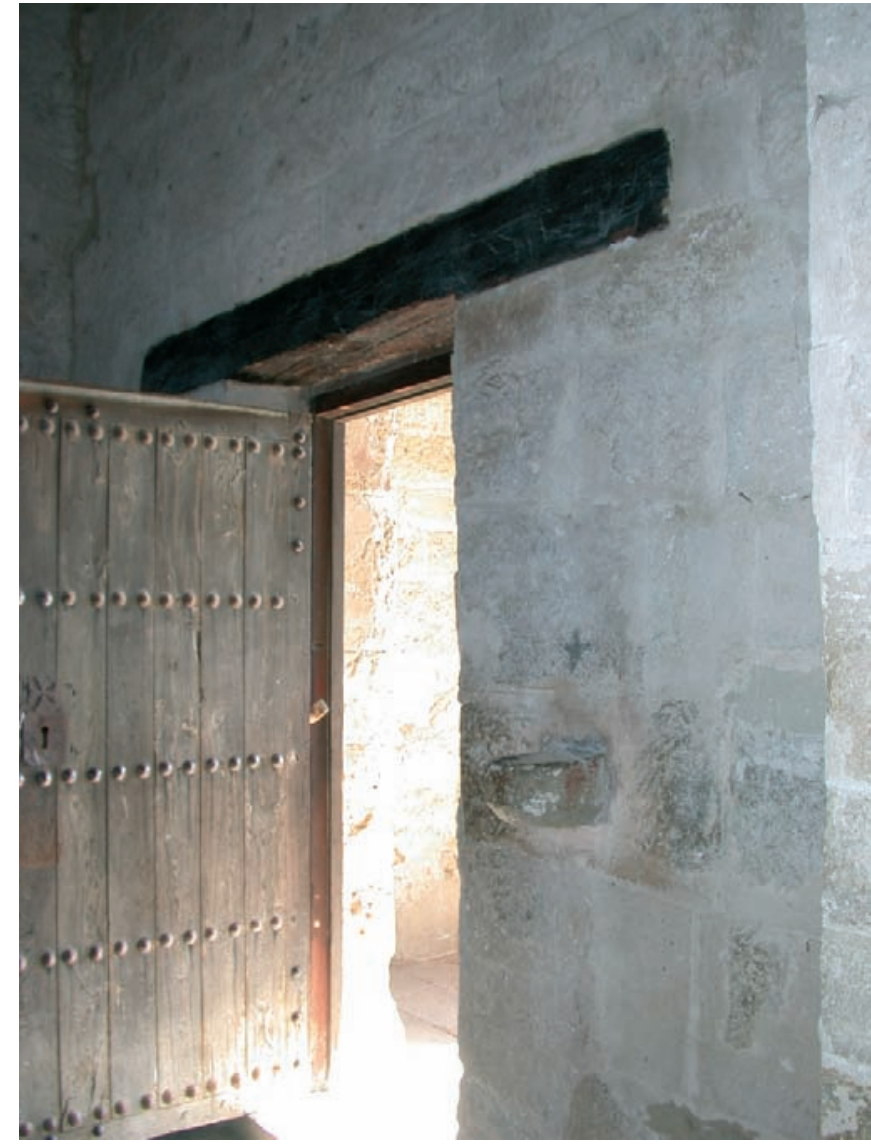

Fig. 13. Dinteles del acceso oeste de S. Juan de Baños. Labrados a hacha, presentan largos empotramientos en el muro que sobrepasan la luz del vano

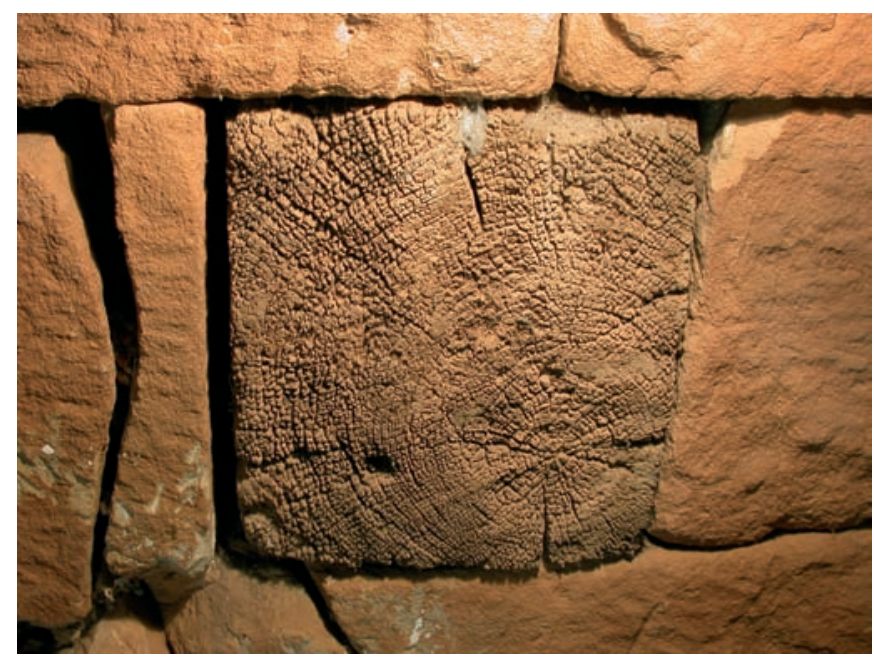

Fig. 14. Testa de la viga sur de Quintanilla de las Viñas: pieza enteriza que se labró con perfecto ajuste con los sillares. Muestra una degradación superficial que indica una acción prolongada del sol y la lluvia (surcos de $10 \mathrm{~mm}$ de calado), por lo que este paramento tuvo que estar durante mucho tiempo sometido a la intemperie

la parte externa de albura con objeto de que las piezas sean casi íntegramente de duramen, mejorando al máximo las propiedades de dureza, estabilidad y resistencia a la degradación. Al mismo tiempo, este labrado de calidad se corresponde con su uso como elementos estructurales que realizan funciones comprometidas, como cargaderos (Baños, Barriosuso; figura 13), tirantes (Baños) y atado y transmisión de cargas (La Nave, Quintanilla; figura 14).

Al igual que sucedía con la elección de madera, este tipo de labra parece intencionado y refleja un modo constructivo que podría formar parte de una tradición de trabajo de la madera. Su yuxtaposición a los caracteres ecofactuales, dos criterios aunados para una elaboración de calidad, nos lleva a interpretar que corresponden a un mismo momento constructivo. En ninguno de los edificios se observa este tipo de labra en maderas de cronología posterior -lo que sería prueba positiva de dos momentos constructivos-; si bien esta ausencia podría explicarse por el mismo efecto de degradación diferencial antes referido. A falta de evidencias estratigráficas, consideramos que el labrado es original y realizado de inmediato tras el corte de la madera y, por consiguiente, proponemos como hipótesis la existencia de una unidad eco-artefactual en el conjunto del material. Conforme a esta hipótesis, la eventual reutilización de piezas no habría alterado sustancialmente la escuadría de cada elemento, ya que el nuevo uso no precisaría un relabrado intenso, sino uno más somero con objeto de ajustar cada pieza a su nueva posición y función, tal como pudo suceder con la viga de La Nave (ALONSO et al., 2004; figura 15).

Resta por desarrollar el análisis de la relación entre artefactos y contexto en cada uno de estos edificios; al igual que el ya realizado en S. Pedro de La Nave (AlONSO et al., 2004). Las dataciones artefactuales anteriores fijan el inicio de un recorrido de uso en uno o en sucesivos edificios y sólo pueden operar, una vez contextualizadas, como indicadores post quem de la actividad constructiva (CABALLERO, 2004). Sin embargo, no es objeto del presente trabajo abordar un análisis contextual en cada uno de los edificios, sino interpretar globalmente las maderas halladas en cuatro edificios diferentes.

En primer lugar, debemos señalar que el estrecho periodo de aprovechamiento que muestran las fechas podría ser sólo aparente, ya que importantes pérdidas de madera en las piezas implicarían un retardo general de fechas y probablemente una dispersión mayor. Asimismo habría que considerar un retardo adicional, que superaría los 100 años, en el supuesto que se confirmara que la madera es pino laricio. Por consiguiente, las fechas propuestas para el primer uso de las maderas datan a las construcciones en que se ubicaron entre los siglos VI y VIII. Se trata, por tanto, 


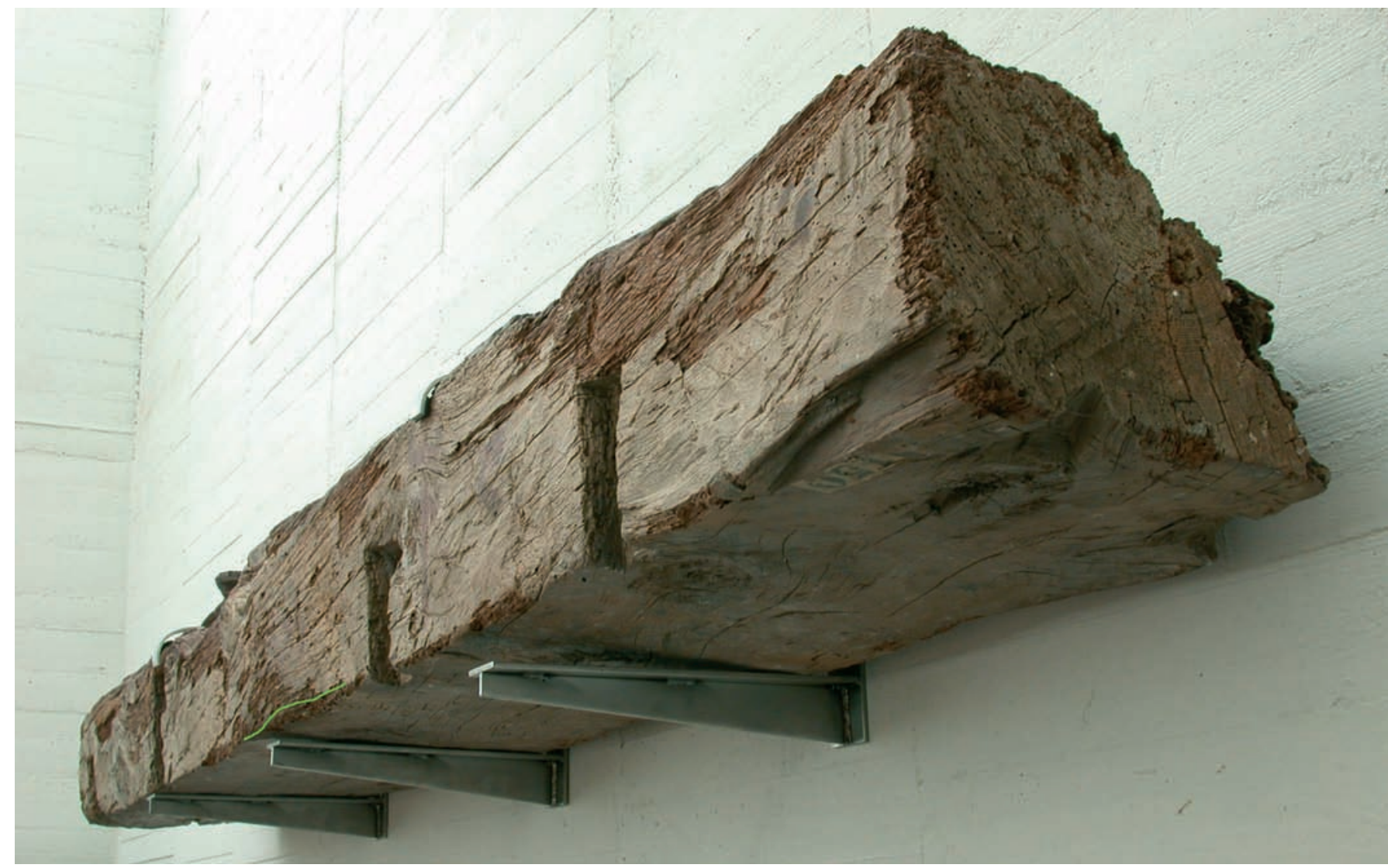

Fig. 15. Viga de S. Pedro de la Nave. El acabado de la cara superior fue muy tosco al igual que su cajeado por utilizarse herramientas de cantero: escoda, trinchante y cortafrío (Alonso LUENGo, cit. Alonso et al., 2004). Tal como señala la línea verde, la superficie se dejó algo abombada en la zona nudosa del centro de la cara, donde no asentaban los sillares por coincidir con la ventana suprabsidial.

de un primer grupo de edificios dispersos en la cuenca media del Duero que, no obstante, comparten un mismo modo constructivo en el uso de la madera.

En segundo lugar, llama la atención el contraste existente entre la homogeneidad del material lígneo y la variedad de modelos estructurales y aparejos que presentan esta serie de iglesias (Utrero, 2004). Tal como indicábamos anteriormente, no sabemos si esta homogeneidad ecoartefactual es una muestra representativa del tipo de madera de uso común en cierto periodo, o si es sólo una casualidad excepcional. Asimismo podemos recurrir a un fenómeno de degradación diferencial ${ }^{9}$ del maderamen para poder explicar la conservación de todas estas piezas a lo largo de más de mil doscientos años.

Averiguar cuál de estos factores ha podido ser el determinante, es una cuestión clave a la hora de discutir la

\footnotetext{
9 Sería más exacto referirse a una conservación diferencial ya que, además de la calidad de la madera, dependería conjuntamente de otros factores como una localización menos propicia a la degradación o la dificultad de ser objeto de expolio en un edificio arruinado.
}

posible reutilización de estas maderas. En la mayoría de las iglesias altomedievales ha habido reutilizaciones de material pétreo y se ha documentado en muchos casos la ruina del edificio original (CABALlero y Utrero, 2005). Sería por ello plausible que también se hubiera reutilizado madera; pero habría que explicar por qué todo el material recuperado pertenece al mismo tipo de madera. Sería aceptable si esta madera hubiese sido de uso común en época anterior e incluso, si se hubiesen expoliado edificios de igual o próximo emplazamiento, en los que se habría utilizado casualmente la misma madera. En este aspecto, destaca Baños por el grueso tirante conservado, que podría ser representativo del maderamen de sus cubiertas. Con parecida verosimilitud, se podría interpretar también que el reaprovechamiento consistió en un expolio selectivo de este tipo de madera buscada ex profeso en construcciones más o menos distantes. En este supuesto, podríamos afirmar que el material habría vuelto a operar como especie-guía en una nueva actividad constructiva, pero desprovisto, claro está, de la información cronológica ligada a su primer uso. 
Por el contrario, la explicación a partir de una conservación diferencial resulta poco verosímil, pues todas las piezas habrían tenido que superar un periodo de ruina en condiciones propicias a su rápida degradación y, tras ser recuperadas junto a otros elementos de caracteres y cronología distintos, serían los únicos elementos lígneos que lograran conservarse hasta hoy. En definitiva, cualquiera que sea nuestra lectura, una explicación que sea alternativa al simple azar deberá basarse en dos factores —uso selectivo y/o conservación diferencial- para poder comprender el uso constructivo que tuvo un material tan singular.

\section{ALGUNAS CONCLUSIONES}

En el presente trabajo se han tratado aspectos significativos del ciclo constructivo de las maderas de pino silvestre/ laricio, lo que nos ha proporcionado nuevos elementos de discusión acerca de la historia cultural y natural del material lígneo. En un orden metodológico, hemos partido de la identificación taxonómica y cronológica del material para llegar a establecer las zonas geográficas de procedencia de estas especies de madera. Para ello, aportamos nuevos criterios de diferenciación anatómica que han permitido identificar como pino laricio la techumbre original de la Mezquita de Córdoba y las restauraciones históricas de la Alhambra, entre otras construcciones. Asimismo se han identificado como pino silvestre la techumbre del claustro bajo del Monasterio de Silos y diversas construcciones medievales de la Meseta septentrional. También nos hemos servido de la datación dendrocronológica como indicador cronológico específico de la madera y se ha podido datar diversas construcciones medievales de Castilla y Andalucía. Allí donde no se disponía de cronologías de referencia, se ha recurrido al carbono-14 que ha proporcionado además una primera datación de largas cronologías flotantes, que cubren casi todo el primer milenio: un primer tramo entre 71 y 543 d. C. (pino silvestre/laricio), y otro entre 568 y 1086 d. C. (pino laricio).

No siempre es posible determinar el origen geográfico del material mediante un método empírico como la dendrocronología, por lo que es necesario recurrir a fuentes documentales que deben usarse críticamente, dada la imprecisión de los nombres de procedencia. Se constata que tradicionalmente la madera de pino laricio se ha denominado pino de Cuenca y pino de Segura, y que estos orígenes van unidos históricamente a su transporte por las vías fluviales del Tajo, Guadalquivir, Segura, etc. Algunos nombres de madera son imprecisos, como la voz alerce, que se ha referido, según los lugares y momentos, a distintas especies, como cedro, pino, enebro, sabina, etc., e incluso ha sustituido al nombre original lárice para designar a Larix decidua. Todas las maderas llamadas alerce son aromáticas y/o resinosas y tienen propiedades imputrescibles que les confieren gran valor de uso. El pino laricio de la techumbre de la Mezquita de Córdoba ha sido también denominado pino alerce, pero no hemos visto aplicado este nombre al pino silvestre.

La disponibilidad del recurso ha mostrado ser un condicionante importante del uso de la madera. Por un lado, explica un uso selectivo en función del valor resistente de cada especie, tal como se ha observado en la Alhambra y el Cuarto Real de Sto. Domingo de Granada. Por otro lado, puede ser causa de que el material lígneo se convierta en especie-guía, es decir, un indicador cronológico basado en el uso de un tipo de madera asociado a un determinado periodo y contexto constructivo. La madera de laricio opera como especie-guía a partir de 1492 en el conjunto de la Alhambra e igualmente la madera de silvestre/laricio se comporta como especie-guía a lo largo del primer milenio en edificios castellanos. Por otra parte, las dataciones artefactuales que hemos obtenido en estos edificios han servido para establecer una acotación post quem de su construcción: 476-536 cal AD (Quintanilla de las Viñas), 569-619 cal AD (Santa Cecilia de Barriosuso), 499-595 cal AD (San Pedro de La Nave) y 499-595 cal AD (San Juan de Baños).

Estos restos lígneos prueban la existencia espontánea de pinares de silvestre y/o laricio en la meseta norte a lo largo del primer milenio. La datación del anillo de mayor edad, 131 cal $A D$ ante quem, y la del anillo de menor edad, 569 cal $A D$ post quem, delimitan el periodo en que fueron un recurso lígneo de la arquitectura de la cuenca media del Duero. Su localización más tardía, hasta hoy conocida, está en el sur de Burgos (Barriosuso, 569-619 cal AD post quem), pero plausiblemente estas viejas masas, de acusada continentalidad y crecimiento mínimo, no debieron tardar en desaparecer por efecto, sin duda, de la acción antrópica.

\section{Bibliografía}

Aguirre, F. J.; JiméneZ, M. C., 1979: Introducción al Jaén Islámico. Estudio Geográfico-Histórico. Instituto de Estudios Gienenses. Diputación Provincial de Jaén. 291 pp.

Alejano Monge, R., 2005: Distribución de Pinus nigra Arn. subs. salzmannii en las Sierras Béticas. Importancia de los relictos de las Sierras de Tejeda y Almijara.

AL-IDRISI, 1154: Kitab Nuzhat al-mustaq, Geografía de España, traducción de E. Saavedra y A. Blázquez, Valencia, 1974.

Almagro Gorbea, A., 2002: El análisis arqueológico como base de dos propuestas: El Cuarto Real de Santo Domingo (Granada) y el Patio del Crucero (Alcázar de Sevilla), Arqueología de la Arquitectura, 1, pp.175-192.

Almagro Gorbea, A., 2008: Palacios Medievales Hispanos. Real Academia de Bellas Artes de San Fernando, Madrid. 
Alonso, F.; Rodríguez, E.; Rubinos, A., 2004: Datación de madera constructiva en San Pedro de la Nave (Zamora) y su interdatación con San Juan de Baños (Palencia). En Caballero (ed.): La Iglesia de San Pedro de la Nave. Zamora, pp. 209-237.

Aranda y Antón, G., 1990: Los bosques flotantes. Historia de un roble del siglo XVIII. ICONA, Madrid, $231 \mathrm{p}$.

Arbeiter, A., 2001: Disposición y construcción del Templo. En: BArroso, E. y Morín, J.: La iglesia de Santa María de Quintanilla de las Viñas. Ediciones B.M.M. \& P, pp. 45-78.

Arroyo, F., 1998: Agua, paisaje y sociedad en el siglo XVI según las Relaciones Topográficas de Felipe II, Madrid, Ediciones del Umbral.

BlázQueZ, J. M., 1996: España Romana. Cátedra.468 pp.

Buxó, R., Piqué, R., 2008: Arqueobotánica. Los usos de las plantas en la península ibérica. Ariel Prehistoria, $268 \mathrm{pp}$.

Caballero, L.; ArCe, F., 1997: La iglesia de San Pedro de La Nave (Zamora). Arqueología y arquitectura, Archivo Español de Arqueología, 70, 221-274.

Caballero, L.; Feijoo, S., 1998: La iglesia altomedieval de San Juan Bautista en Baños de Cerrato (Palencia), Archivo Español de Arqueología, 71, 181-242.

Caballero Zoreda, L., 2000: Aportación a la arquitectura medieval española. Definición de un grupo de iglesias castellanas, riojanas y vascas. Actas del V Congreso de Arqueología Medieval Española, Valladolid, 1999,V. 1, pp. 211 233.

Caballero Zoreda, L., 2004: Una experiencia en Arqueología de la Arquitectura, Arqueología de la Arquitectura, 3, 127-143.

Caballero, L.; Utrero, M. Á., 2005: Una aproximación a las técnicas constructivas de la Alta Edad Media en la Península Ibérica. Entre visigodos y omeyas, Arqueología de la Arquitectura, 4, 169-192.

Candelas, A. L., 2001: Carpintería de lo blanco onubense. Diputación de Huelva. 242 pp.

Carabaza, J. M.; García, E.; Esteban, J.; JiméneZ, A., 2004: Árboles y Arbustos de al-Andalus. Estudios Árabes e Islámicos. Monografía: 8. C.S.I.C., 349 pp.

Carle, M. C., 1976: El bosque en la edad Media, Cuadernos de Historia de España.

Catalán, G.; Gil, P.; Galera, R.; Martín, S.; Agúndez, D.; Alía, R., 1991: Regiones de Procedencia de Pinus sylvestris L. y Pinus nigra Arn. subs. salzmannii (Dunal) Franco en España. ICONA.

Ceballos, L.; Ruiz de la Torre, J., 1979: Árboles y Arbustos de la España Peninsular. E.T.S.I. de Montes. Madrid, 512 pp.

Collantes de Terán, A., 2001: De Betis a Guadalquivir: la victoria de Mercurio. En: Itinerarios Medievales e Identidad Hispánica. XXVII Semana de Estudios Medievales, Estella, pp.159-188.

Creus, J.; Puig De FÁBregas, R., 1983: Climatología histórica y dendrocronología de Pinus nigra Arn., Avances sobre Investigación en Bioclimatología, pp. 121-128. Zaragoza.

Cruz Aguilar, E., 1987: El negociado de maderas de Segura en Sevilla. En: Historia, Instituciones, Documentos, n. ${ }^{\circ}$ 14. pp. 225-274. Universidad de Sevilla.

ESCUDERO, Z., 1995: Nuevos estudios sobre el poblado vacceo de «El Soto de Medinilla» (Valladolid), en: Delibes, G., Romero, F. y Morales, A. (eds.), Arqueología y Medio Ambiente. El primer milenio A.C. en el Duero Medio, Valladolid, 179-217.

Esparza Arroyo, A., 1995: La Primera Edad del Hierro, en Historia de Zamora, tomo I, Diputación de Zamora, Instituto de Estudios Zamoranos «Florián de Ocampo» y Caja España, Zamora, 103-149.

FernándeZ García, R., 1996. Historia del Jardín Sevillano: recopilación y edición crítica de fuentes. Tesis Doctoral. Universidad de Sevilla.

Fernández-Golfín, J. I.; Díez, M. R,; BaOnZA, M. V.; Gutiérrez, A.; HerMoso, E.; CONDE, M.; VAN DEN Eynde, V., 2001: Caracterización de la calidad y las propiedades de la madera de pino larico (Pinus nigra Arn. salzmannii). Investigación Agraria: Sistemas y Recursos Forestales, 10 (2), pp. 311 331.

FORD, R., 1988 (1845): Manual para viajeros por Andalucía y lectores en casa. Reino de Córdoba. Ediciones Turner.

Franco, F.; García, M.; Génova, M. M.; Maldonado, J.; Morla, C.; Sainz, H., 2001: The Holocene history of Pinus forests in the Spanish Northern Meseta, The Holocene 11, 3 pp. 343-358.
García Antón, M.; Franco, F.; Maldonado, J.; Morla, C. y Sainz, H., 1997: New data concerning the evolution of the vegetation in Lillo pinewood (León, Spain), Journal of Biogeography, 26, 1-7.

García de Cortazar, J. A., 1973: La época medieval. Historia de España Alfaguara II. Alianza Universidad, 530 pp.

García GuZmán, M. M., 1985: El Adelantamiento de Cazorla en la Baja Edad Media. Universidad de Cádiz. 406 pp.

Gil OlcinA, A., 2006: Importancia y desaparición de un uso tradicional del agua: la flotación de maderas, Ería, 69, pp. 57-74.

Gómez Bravo, J., 1778: Catálogo de los obispos de Córdoba. Tomo I.

Gómez Cruz, M., 1991: Atlas Histórico-Forestal de Andalucía. Siglo XVIII. Universidad de Granada, 71 pp.

Gómez-Mercado, F.; Valle, F., 1990: Notas Fitosociológicas sobre las Comunidades Arbóreas de las Sierras de Cazorla y Segura, Acta Botánica Malacitana, 15, pp: 239-246.

GómeZ-Moreno Martínez, M., 2001: La carpintería en Granada. Documentos y Estudios de Arte Granadino. Instituto Gómez-Moreno de la Fundación Rodríguez-Acosta. Granada, 194 pp.

GonzÁlez Gómez, A., 1984: Huelva en la Edad Media. Un enclave fronterizo. En: Huelva y su provincia. Tartesos, pp. 10-89.

HernándeZ JimÉneZ, F., 1928: Arte musulmán. La techumbre de la Gran Mezquita de Córdoba. Archivo español de Arte y Arqueología, IV, 12, pp. 191-225.

IBÁN̄EZ MartíneZ, P. M., 2003: La vista de Cuenca desde el oeste (1565) de van den Wyngaerde. Diputación de Cuenca, 405 p.

KaGAN, R. L., 1986: Ciudades del Siglo de Oro. Las vistas españolas de Antón van den Wyngaerde. Ediciones El Viso.

LACARrA, J. M., 1980: Acerca de las fronteras en el valle del Ebro (s. VIII-XII). En la España Medieval. Estudios dedicados a D. Julio González, Madrid, pp. 181-191.

LÉVI-ProvenÇAL, E., 1953: Description de l' Espagne d' Ahmad al-razi, essai de reconstitution de l'original arabe et traduction française, Al-Andalus, 18, pp. 51-108.

LÓpeZ Almansa, J.C., 1999: Aprovechamientos forestales y evolución de la vegetación en el macizo del Segura. Cuadernos de la S.E.C.F., 8, pp. 67-74.

MALPICA, A.; BERMÚDEZ, J., 2003: Transformaciones cristianas de la Alhambra. http://192.167.112.135/NewPages/COLLANE/TESTIBDS/MUTAMENTI

Morales, A. de., 1575: Las Antigüedades de las ciudades de España, Madrid 1792 t X.

Morgado, A. de., 1981 (1587): Historia de Sevilla. Edición facsímil. C.O.A.A.T de Sevilla.

Muñoz Sobrino, C., 2001: Cambio climático y dinámica del paisaje en las montañas del noroeste de la Península Ibérica.Tesis doctoral, Universidad de Santiago de Compostela (manuscrito).

Muñoz, C.; Ramil-Rego, P.; Rodríguez Guitián, M., 1997: Upland vegetation in the north-west Iberian peninsula after the last glaciation: forest history and deforestation dynamics. Vegetation History and Archaeobotany, 6, 215-233.

Mutz, R.; Guilley, E.; Sauter, U.H.; Nepveu, G., 2004: Modelling juvenilemature wood transition in Scots pine (Pinus sylvestris L.) using nonlinear mixed-efects models. Ann. For. Sci. 61, pp. 831-841.

NAVARRO, F.B., 1998: Importancia ecológica de los pinares.

Nuere, E., 2008: La Carpintería de Armar Española. Editorial Munilla-lería, Madrid. 383 pp.

Oria de Rueda, J.A., 1996: Memoria del Mapa Forestal de España. Hoja 5-3: Burgos, MAPA-ICONA, Madrid.

OrinuelA, A., 1996: Casas y Palacios Nazarís. Siglos XIII-XV. El legado Andalusí. Lunwerg Ediciones, 388 pp.

PAlacios, P., 1997: Anatomía de maderas de coníferas a nivel de especie. Región norteamerica y europea. Tesis Doctoral. ETSI de Montes.

Piqueras, J.; SANChís, C., 2001: El transporte fluvial de madera en España. Geografía histórica, Cuadernos de Geografia, 69/70, pp. 127-162.

Ramil-Rego, P.; Muñoz, C.; Gómez-Orellana, L. Fernández, C., 2001: Historia ecológica de Galicia: modificaciones del paisaje a lo largo del Cenozoico, SEMATA, Ciencias Sociais e Humanidades, 13, 67-103.

Richter, K.; RodrígueZ, E., 1986: El Banco de datos dendrocronológicos para la Península Ibérica, Koiné, 1 pp. 66-77. 
Rodríguez Ruiz, D., 1992: Las Antiguedades Árabes de España. Fundación Cultural COAM. Madrid, 303 pp.

Rodríguez Trobajo, E., 1996: Estudio dendrocronológico de la Alhambra y el Generalife. INIA-Patronato de la Alhambra y Generalife.

Rodríguez Trobajo, E., 2006: Estudio dendrocronológico de la Torre del Salvador y del Cobertizo Doncellas, 2. INIA-Consorcio de la Ciudad de Toledo.

Rodríguez Trobajo, E.; Ortega Quero, M., 2006: Tendencias radiales de la densidad y sus componentes en Pinus nigra Arn. de la Península Ibérica, Investigación Agraria: sistemas y Recursos Forestales, 15 (1), pp. 120133.

Roig, S.; Gómez, F.; Masedo, F.; Morla, C.; SÁnchez, L. J., 1997: Estudio paleobotánico de estróbilos y maderas subfósiles holocenas en el yacimiento de Cevico Navero (Palencia, España), Anales del Jardín Botánico 55 (1): pp. 111-123.

RUIZ De la ToRre, J., 1979: Árboles y arbustos de la Península Ibérica. E. T. S. De Ingenieros de Montes, Madrid. $512 \mathrm{pp}$.

Ruiz de la Torre, J., 1991: Memoria del Mapa Forestal de España. Hoja 3-4. Alcañices, MAPA-ICONA, Madrid.

Sánchez Hernando, L. J.; Gómez Manzaneque, F.; Masedo, F.; Morla, C. y DEL NIDO, J., 1999: Identificación de macrorrestos holocenos en las cuencas altas de los ríos Porma, Curueño y Esla (León, España), Boletín de la Real Sociedad Española de Historia Natural (Biologia), 1-2, 31-42.

SÁNCHEZ MARTíNEZ, M., 1988: Comercio nazarí y piratería catalano-aragonesa (1344-1345). En GarcÍA-Arenal, M. y Viguer, M.J. (ed.): Relaciones de la Península Ibérica con el Magreb (siglos xiii-xvi) C.S.I.C. Instituto HispanoÁrabe de Cultura.
SANChís, C.; Piqueras, J., 2001: La conducció fluvial de fusta a València (segles XIII-XX), Cuadernos de Geografia, 69/70, pp.195-214.

SAnZ, C. y Escudero, Z., 1995: El conjunto arqueológico de Padilla/Pesquera de Duero (Valladolid). Evolución del asentamiento durante la etapa indígena, en Delibes, G.; Romero, F. y Morales, A. (eds.), Arqueología y Medio Ambiente. El primer milenio A.C. en el Duero Medio, Junta de Castilla y León, Valladolid, 271-306.

SAntiago, R., 1995: Memoria del Mapa Forestal de España. Hoja 6-4: Soria, MAPA-ICONA, Madrid.

SigüENZA, Fray José de, 1600: La fundación del Monasterio de El Escorial. Historia de la Orden de San Jerónimo, libro tercero. Ediciones Turner, 1988. ToRres Balbás, L., 1957: Arte Hispanomusulmán hasta la caída del Califato de Córdoba. En: Historia de España, dir. Menéndez Pidal, tomo V. Madrid.

VAlLE, F., 1979: Flora y Vegetación de las Sierras de Alfacar y Víznar, Huétor y la Yedra. Tesis Doctoral. Universidad de Granada.

Utrero Agudo, M.a Á., 2004: Iglesias Tardoantiguas y Altomedievales en la Península Ibérica. Análisis Arqueológico y Sistemas de Abovedamiento. Tesis Doctoral. Universidad Autónoma de Madrid.

Weninger, B., 1997: Monte Carlo wiggle matching. Zur statistischen auswetung der Mittelneolithischen ${ }^{14} \mathrm{C}$-daten von Hasselsweiler 2, Inden 3, and Inden 1. En: BIERMANN E., editor: Grobgartach und Oberlauterbach. Interregionale Beziehungen im süddeutschen Mittelneolithikum. Archäologische Berichte, 8, p. 91-113.

Recibido: 9 de octubre de 2008 Aceptado: 13 de enero de 2009 